\title{
HERBACEOUS FEEDSTOCK 2020 STATE OF TECHNOLOGY REPORT
}

\section{September 2020}

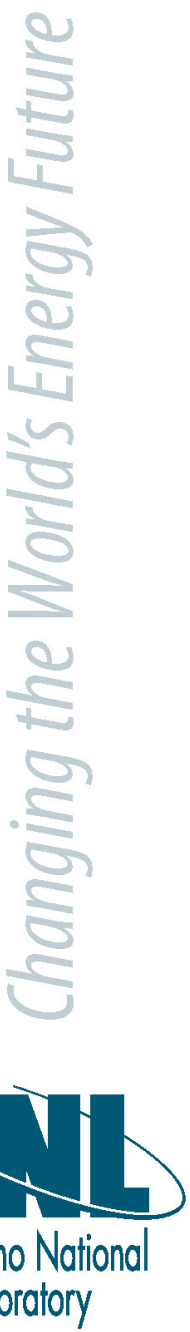

Yingqian Lin, Mohammad Sadekuzzaman Roni, David N Thompson, Damon S Hartley, Mike Griffel, Hao Cai

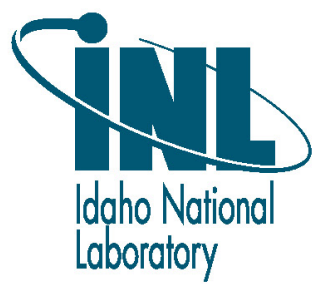




\section{DISCLAIMER}

This information was prepared as an account of work sponsored by an agency of the U.S. Government. Neither the U.S. Government nor any agency thereof, nor any of their employees, makes any warranty, expressed or implied, or assumes any legal liability or responsibility for the accuracy, completeness, or usefulness, of any information, apparatus, product, or process disclosed, or represents that its use would not infringe privately owned rights. References herein to any specific commercial product, process, or service by trade name, trade mark, manufacturer, or otherwise, does not necessarily constitute or imply its endorsement, recommendation, or favoring by the U.S. Government or any agency thereof. The views and opinions of authors expressed herein do not necessarily state or reflect those of the U.S. Government or any agency thereof. 


\title{
HERBACEOUS FEEDSTOCK 2020 STATE OF TECHNOLOGY REPORT
}

\author{
Yingqian Lin, Mohammad Sadekuzzaman Roni, David N Thompson, Damon S \\ Hartley, Mike Griffel, Hao Cai
}

September 2020

Idaho National Laboratory
Idaho Falls, Idaho 83415

http://www.inl.gov

Prepared for the U.S. Department of Energy Under DOE Idaho Operations Office

Contract DE-AC07-05ID14517 


\title{
HERBACEOUS FEEDSTOCK 2020 STATE OF TECHNOLOGY REPORT
}

\author{
Yingqian Lin, Mohammad Roni, \\ David N. Thompson, Damon Hartley, \\ L. Mike Griffel, Hao Cai
}

SEPTEMBER 30, 2020 


\section{Idaho National Laboratory}

\begin{tabular}{|c|c|}
\hline $\begin{array}{l}\text { Type: Milestone } \\
\text { WBS \#: } 1.1 .1 .2\end{array}$ & $\begin{array}{l}\text { Scheduled Completion: September 30, } 2020 \\
\text { Platform Area: Feedstock Technologies }\end{array}$ \\
\hline Milestone Title: & $\begin{array}{l}\text { Herbaceous Feedstock } 2020 \text { State-of-Technology/Develop and } \\
\text { Update the State-of-Technology Report }\end{array}$ \\
\hline Authors: & $\begin{array}{l}\text { Yingqian Lin, Mohammad Roni, David N. Thompson, Damon } \\
\text { Hartley, L. Mike Griffel, Hao Cai }\end{array}$ \\
\hline $\begin{array}{l}\text { Project Name: } \\
\text { Project Leader: }\end{array}$ & $\begin{array}{l}\text { Feedstock Supply Chain Analysis } \\
\text { David N. Thompson }\end{array}$ \\
\hline Participating Researchers: & $\begin{array}{l}\text { Technical data (Appendix A): Neal Yancey, Jaya Tumuluru, William } \\
\text { Smith, and Lynn Wendt (all from INL) } \\
\mathrm{n}^{\text {th }-S u p p l y ~ S c e n a r i o ~(A p p e n d i x ~ B): ~ T a s m i n ~ H o s s a i n ~(N C ~ S t a t e), ~} \\
\text { Daniela Jones (NC State, INL), Damon Hartley (INL), Mike Griffel } \\
\text { (INL), Yingqian Lin (INL), Pralhad Burli (INL), David N. Thompson } \\
\text { (INL), Matthew Langholtz (ORNL), Maggie Davis (ORNL), Craig } \\
\text { Brandt (ORNL) }\end{array}$ \\
\hline Key Words: & analysis, state of technology, $\mathrm{n}^{\text {th }}$-plant, feedstock, herbaceous \\
\hline
\end{tabular}

\section{EXECUTIVE SUMMARY}

The U.S. Department of Energy (DOE) promotes the production of advanced liquid transportation fuels from lignocellulosic biomass by funding fundamental and applied research that advances the State of Technology (SOT). As part of its involvement with this mission, Idaho National Laboratory (INL) completes an annual SOT report for biomass feedstock logistics. This report summarizes supply system impacts of Bioenergy Technologies Office (BETO)-funded research and development efforts at INL and elsewhere (such as the High-Tonnage Feedstock Logistics projects (Webb et al. 2013a, Webb et al. 2013b, Webb et al. 2013c, Webb and Sokhansanj 2014, Sokhansanj et al. 2014)) that lead to improvements in feedstock supply systems. These include improvements to and observed performance of innovative harvest and collection methods, storage technologies, transportation and handling approaches, and advanced preprocessing technologies. Biomass quality and variability, and the interface between feedstock quality and conversion performance are key drivers in addition to delivered feedstock cost. In this report, we estimate the benefits of $R \& D$ technology improvements to individual supply system unit operations and present the status of feedstock logistics technology development for converting herbaceous biomass into biofuels. These analyses are supported by experimental data where possible and help to align the SOT relative to the cost goals defined in the Multi-Year Plan.

The 2020 Herbaceous SOT incorporates an actively managed storage system for earlyharvested bales which are typically $>30 \%$ moisture. The storage system utilizes a combination 


\section{Idaho National Laboratory}

of best management practices and "farm-scale technologies" such as enhanced in-storage drying to achieve storage stability objectives. A wrapped-bale mechanical ventilation concept for these very wet bales utilizes a combination of microbial self-heating and advective air flow (supplied by a commercial grain dryer blower) to reduce stack moisture from $30 \%$ to $<20 \%$ in 30 days. This technical improvement positively affects storage dry matter loss and feedstock preprocessing performance within the feedstock logistics system.

Previous SOT results have confounded biomass supply assumptions from BT-16 that predicted an increasing supply year on year. To get a clearer presentation of cost impacts of technology improvements, in the 2020 SOT we utilized the same supply curves from BT-16 that were used for the 2019 SOT. The 2020 Herbaceous SOT report documents the current modeled cost of an herbaceous feedstock supply system from harvest to the pretreatment reactor throat for hydrocarbon fuel production via biochemical conversion, based on equipment and processes now available or potentially available in the near term. The modeled cost also considers both the required quality and the availability of the biomass resources. The 2020 Herbaceous SOT predicts a modeled delivered feedstock cost of $\$ 80.10 /$ dry ton $(2016 \$)$; this is a $\$ 1.27$ /dry ton (2016\$) decrease from the 2019 Herbaceous SOT. Technology improvements that contributed to this modeled cost reduction include reduced cost in the feedstock preprocessing caused by reduced moisture from the newly designed field side storage. A greenhouse gas emissions (GHG) assessment was completed by Argonne National Laboratory using the 2020 Greenhouse Gases, Regulated Emissions, and Energy use in Transportation model (GREET), estimating a decrease of $6.68 \mathrm{~kg} \mathrm{CO}_{2} \mathrm{e} /$ ton from the $2019 \mathrm{SOT}$ (84.16 $\mathrm{kg} \mathrm{CO}_{2} \mathrm{e} /$ ton in the $2019 \mathrm{SOT}$ to 77.48 $\mathrm{kg} \mathrm{CO} 2 \mathrm{e} /$ ton in the 2020 Herbaceous Feedstock SOT). This net reduction is attributed to reduced energy consumption in the hammer mill, reduced high emission feedstock used in the blend (less three-pass corn stover), and incorporation of the updated GREET model.

Moving forward in future years, we will implement use of the $\mathrm{n}^{\text {th }}$-supply scenario developed in FY19 and FY20 as a constant supply to focus on improvements due to BETOfunded technology improvements. Hence, in this report we also present the 2020 Herbaceous SOT recast using the supply curves and optimal depot and biorefinery locations determined for the $\mathrm{n}^{\text {th }}$-supply scenario (see Appendix B); this is presented in this report as the 2020 Herbaceous $\mathrm{n}^{\text {th }}$-Supply SOT. Overall, by incorporating the biomass availability and depot locations optimized or the demand-based supply from the POLYSYS demand runs, the delivered feedstock cost decreased by $\$ 1.31$ /dry ton from the 2020 Herbaceous SOT. Noting that this brings the delivered cost below the 2022 Herbaceous Projection, which was based on projected 2022 supply curves from BT-16, it will be necessary to recast the 2022 Herbaceous Projection to the $\mathrm{n}^{\text {th }}$-supply scenario during FY21 to put them on the same supply basis for comparison. It will also be necessary in the future to recast the 2030 Herbaceous Projection of $\$ 71.26 /$ dry ton $(2016 \$)$ to bring the SOTs and targets to the same supply basis. 


\section{Table of Contents}

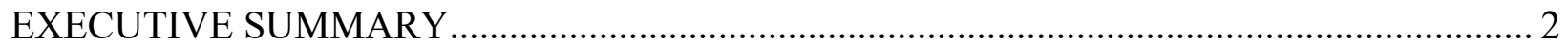

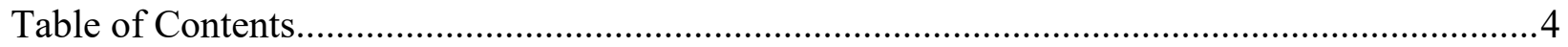

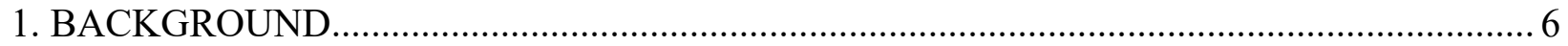

Progression of Feedstock Supply System Designs................................................................... 6

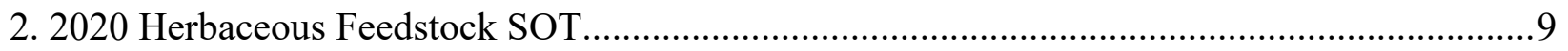

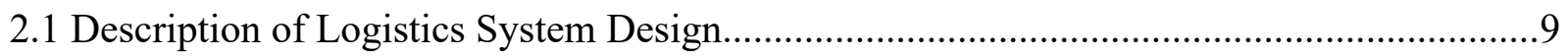

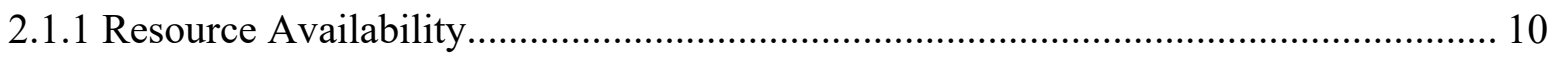

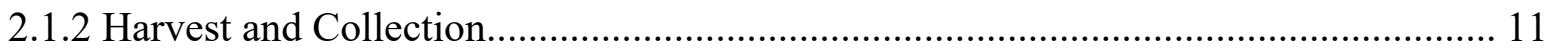

2.1.3 Storage

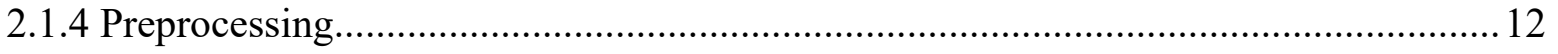

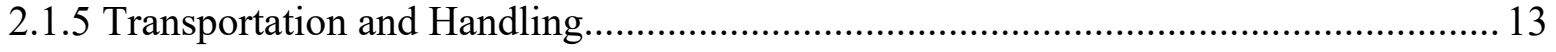

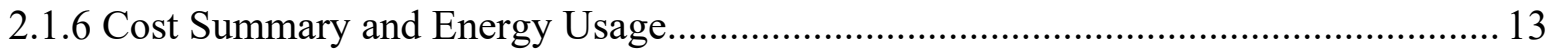

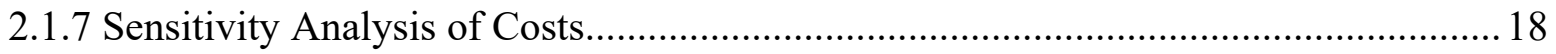

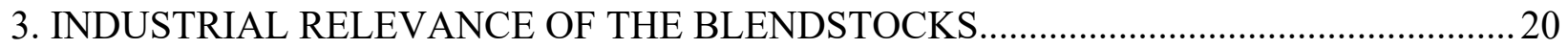

4. QUALIFICATION OF THE BLENDSTOCKS FOR RENEWABLE IDENTIFICATION

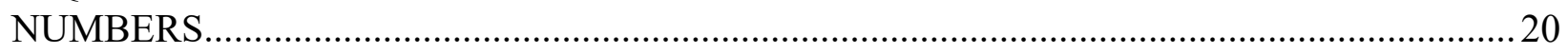

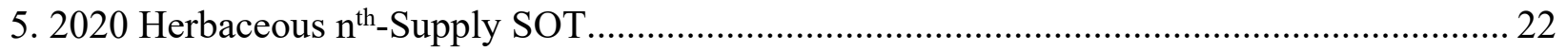

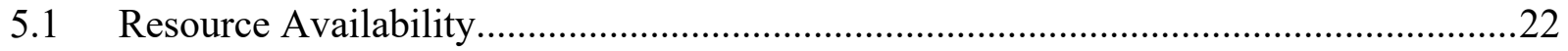

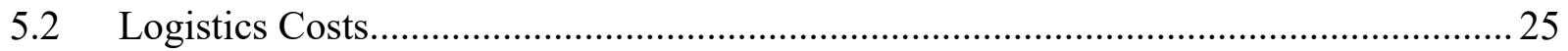

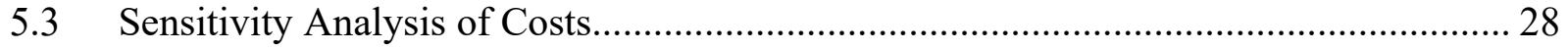

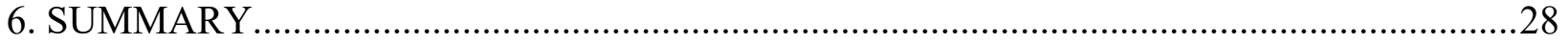

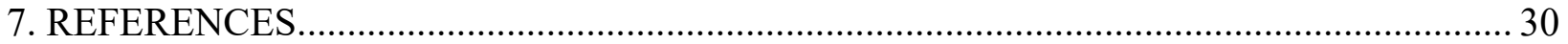

APPENDIX A - 2020 Herbaceous State of Technology Feedstocks Logistics Design and

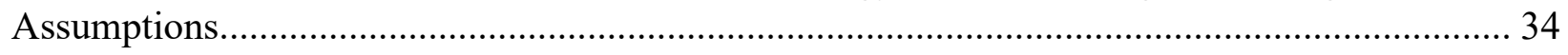

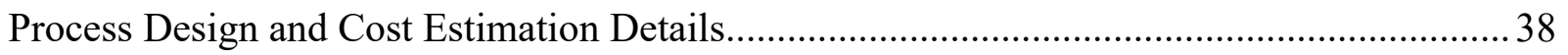

A.1 Interest Rate and Energy Cost Assumptions.....................................................................38 


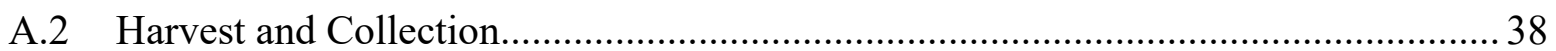

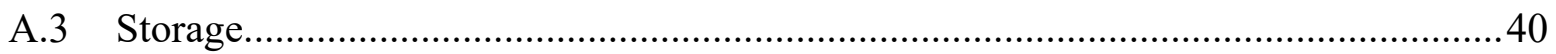

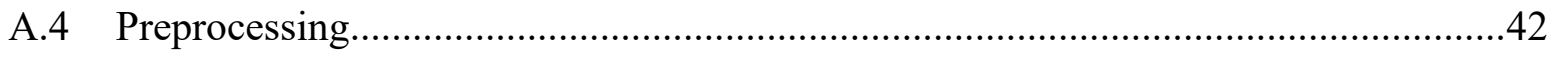

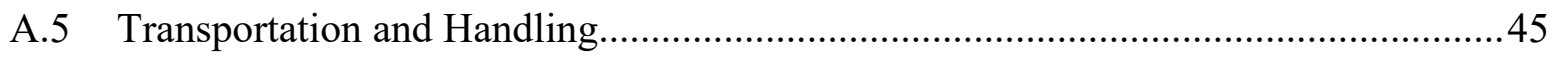

A.6 Depot construction cost for different depot sizes............................................... 49

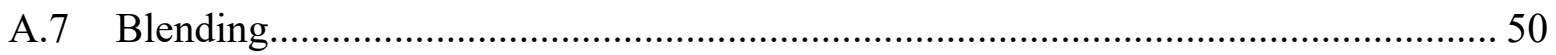

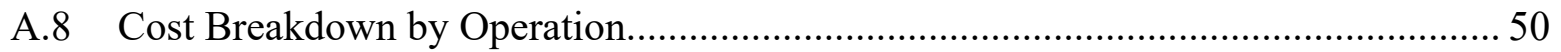

APPENDIX B $-\mathrm{n}^{\text {th }}$-Supply Scenario Assumptions and Analysis...........................................53

B.1 Harmonized herbaceous operational assumptions..................................................... 54

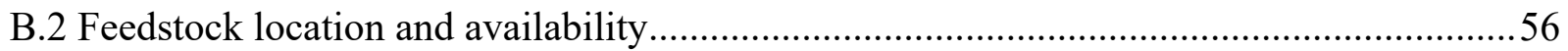

B.3 Reducing the problem size and creating a demand run for POLYSYS ..........................57

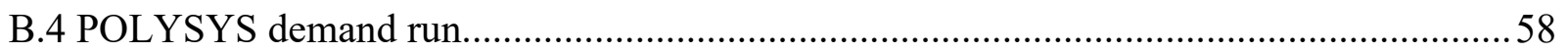

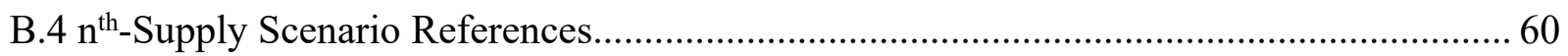




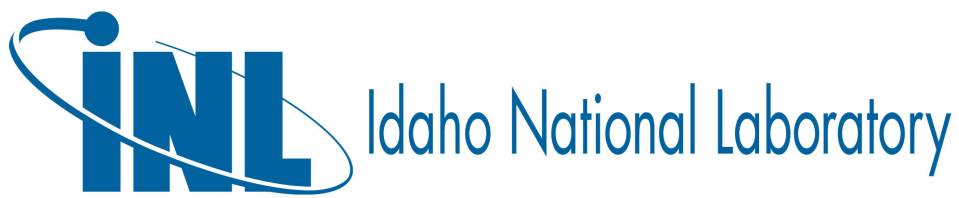

\section{BACKGROUND}

The Energy Independence and Security Act (EISA) of 2007 required a minimum supply of 36 million gallons of renewable fuels per year by 2022. In order to achieve these goals, the Bioenergy Technologies Office (BETO) has set cost and technology targets for producing advanced and cellulosic biofuels. One of the targets is to validate feedstock supply infrastructures and systems with $90 \%$ overall operating effectiveness (Hartley et al. 2020) and field-to-reactor throat delivered cost less than $\$ 85.51 /$ dry ton (2016\$). As stated by the 2017 Multi-Year Program Plan (DOE 2017), the research and development focus of the Feedstock Technologies (FT) platform is reducing the cost, improving the supply chain logistic efficiency, improving biomass quality, and increasing the supply volume. In addition, BETO oversees annual State of Technology (SOT) report that assesses current technologies that are relevant to BETO's targets based on actual data and experimental results.

Feedstocks are essential to achieving BETO goals because the cost, quality, and quantity of feedstock available and accessible at any given time limit the maximum volume of biofuels that can be produced. In accordance with the 2016 Multi-Year Program Plan (DOE 2016a), FT focuses on (1) reducing the delivered cost of sustainably produced biomass, (2) preserving and improving the physical and chemical quality parameters of harvested biomass to meet the individual needs of biorefineries and other biomass users, and (3) expanding the quantity of feedstock materials accessible to the bioenergy industry. This is done by identifying, developing, demonstrating, and validating efficient and economical integrated systems for harvest and collection, storage, handling, transport, and preprocessing raw biomass from a variety of crops to reliably deliver the required supplies of high-quality, affordable feedstocks to biorefineries as the industry expands. The elements of cost, quality, and quantity are key considerations when developing advanced feedstock supply concepts and systems (DOE 2016a).

\section{Progression of Feedstock Supply System Designs}

Feedstock supply systems are highly complex systems of operations required to move and transform biomass from a raw harvested material at the point of production into a formatted, on-spec feedstock at the throat of the conversion reactor. Feedstock logistics can be broken down into individual operations of harvest and collection, storage, transportation, preprocessing, and queuing and handling. Designing economic and environmentally sustainable feedstock supply systems, while providing necessary resource quantities at the appropriate quality, is critical for growth of the bioenergy industry. Research and development on feedstock supply systems aims to reduce delivered cost, improve and preserve feedstock quality, and expand access to biomass resources. Through 2012, BETO-funded research on feedstock supply systems focused on improving conventional feedstock supply systems (CFSS). CFSS designs rely on existing technology and systems to supply feedstock to biorefineries (Hess et al. 2009a). These designs tend to be vertically integrated with a specific conversion process or biorefinery. They also create the requirement to design extremely robust conversion systems capable of handling variability in feedstock quality at the biorefinery. Biorefineries strive to optimize efficiencies and capacities within the constraints of local supply, equipment availability, and permitting requirements. However, this approach makes the system vulnerable to variations in feedstock 


\section{Idaho National laboratory}

quality parameters, such as (a) high ash content, which negatively impacts operating costs related to acid consumption and ash disposal; (b) variable composition of convertible carbohydrates, which negatively impacts sugar yields due to suboptimal enzyme loading; and (c) variable moisture, which increases grinding costs and creates handling and flowability problems that significantly reduce the effectiveness of feedstock introduction to the conversion process.

CFSS designs are currently the backbone of the emerging biofuels industry. However, conventional supply systems have limitations that restrict widespread implementation on a national scale (Hess et al. 2009a, Hess et al. 2009b). Viability of the conventional supply system's design is reliant on geographical areas that have a concentrated supply of abundant, easily accessible, and low-cost biomass resources (such as corn stover in the Midwestern United States). Within these regions, variable weather, inherent compositional variability and harvest practices that are not designed to mitigate quality concerns, such as moisture and ash content, leads to considerable variability in feedstock cost and the biorefinery's ability to process the biomass. Low density bales in conventional systems combined with the short window of availability necessitate large-scale bale storage, leading to greatly increased fire risk. Moving outside these select regions, the feedstock supply system must be further adapted to accommodate a diversity of feedstocks to ensure adequate supply, which leads to changing cost, quality, and conversion yields that are directly tied to the conversion facility's size constraints. CFSS can only address feedstock quality indirectly through passive controls, such as resource selection or best management practices. For example, research at INL has shown that varying harvesting practices and equipment can reduce ash (i.e., dirt) entrainment during harvest and baling (Bonner et al. 2014). When positioned in a highly productive single resource area, biorefineries can be selective in contracting only biomass that meets their specifications. However, biomass quality (e.g., ash and moisture content) is highly variable both spatially and temporally (Kenney et al. 2013), and, in any given year, passive controls might not provide sufficient quality control for the feedstock to meet desired specifications. Therefore, biorefineries that rely on conventional designs are constrained to local resources, with cost-prohibitive expansion of the collection radius limiting plant size (Graham et al. 2013). Several analyses have shown that as the biofuels industry expands past the highly productive regions, CFSS will fail to meet supply requirements (Hess et al. 2009b, Bonner et al. 2014) economically or at the desired price target.

To meet the demands of the future bioenergy industry, the supply system must expand beyond CFSS in certain areas to what has been termed "advanced" feedstock supply systems (Hess et al. 2009a, Hess et al. 2009b, Searcy et al. 2010, Jacobson et al. 2014). For advanced feedstock supply system (AFSS) designs, a distributed network of aggregation and processing centers, termed "depots," are employed near the point of biomass production (i.e., the field or forest) to reduce biomass variability and produce feedstocks of a uniform format, necessary to move toward biomass commoditization (Figure 1). The depots produce a stable, tradable, merchandisable intermediate that reduce downstream conversion inefficiencies and move the burden of feedstock variability away from the biorefinery. 


\section{YII Idaho National Laboratory}

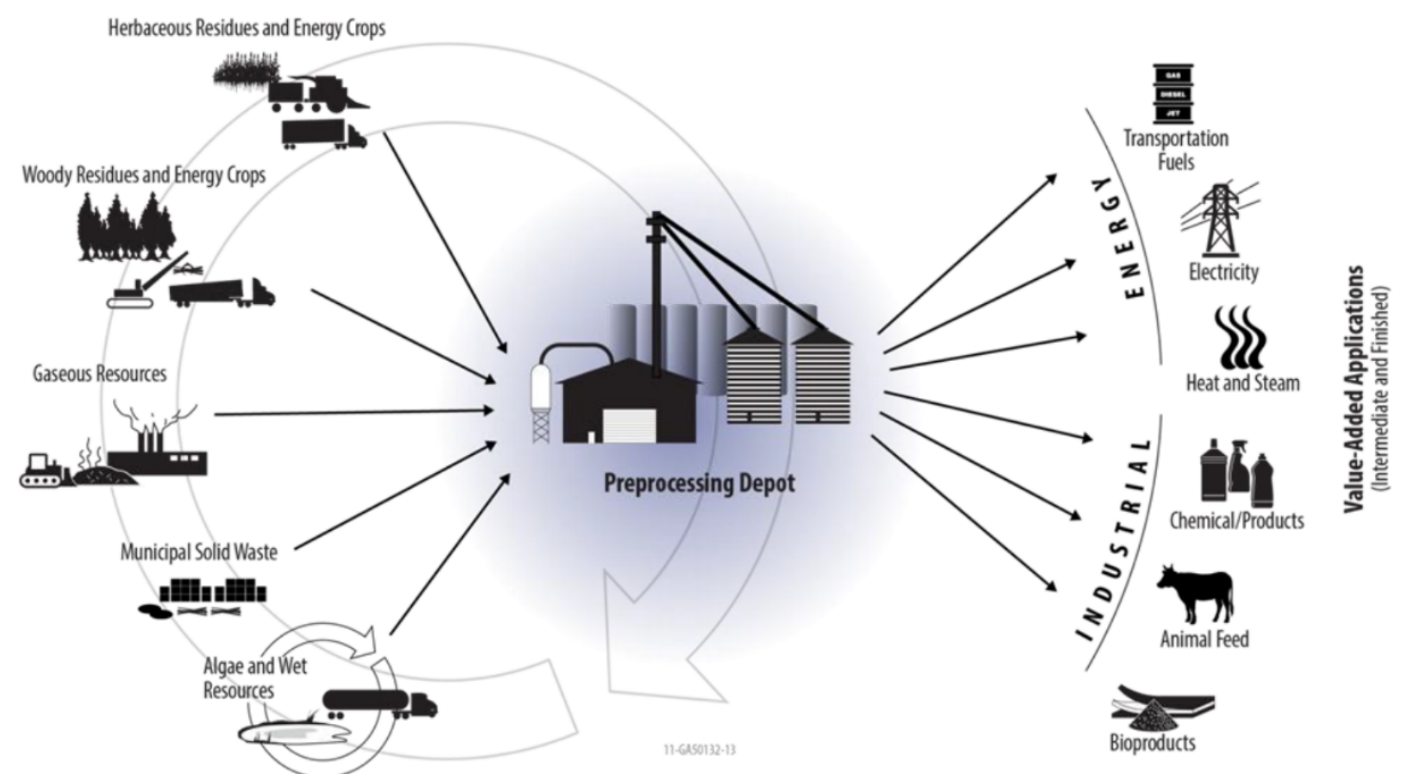

Figure 1. Incorporation of stakeholder feedback has resulted in improvements in advanced feedstock supply systems, evolving depots from being vertically integrated to producing merchandisable intermediates and serving a variety of customers and markets.

Advanced concepts have evolved (and continue to evolve) as new research and ideas emerge. Advanced concepts are also guided by input from stakeholders. In February 2015, the Advanced Feedstock Supply System Validation Workshop gathered experts from industry, DOE offices, DOE-funded laboratories, and academia to discuss approaches for addressing challenges associated with an expanding bioenergy industry and assumptions used in the Advanced Feedstock Supply System. The workshop was sponsored by DOE-BETO and feedback received is being considered as advanced concepts evolve (Searcy et al. 2015).

Depots can provide logistics solutions for sourcing multiple biomass resources to a biorefinery, whether these resources are dispersed or co-located. In such a scenario, depots may emerge as feedstock supply chain business elements to lessen the complexity to a biorefinery of managing a blended feedstock supply system. An economic advantage of a depot in this scenario may be its specialization to supply and preprocess single sources of improved quality, valueadded biomass (referred to as a "blendstock") that can be formulated together with blendstocks from other depots to produce cost-effective feedstocks meeting the specifications of numerous customers. This specialization eliminates the need for a single entity to make a capital investment and establish expertise to contract, preprocess, and supply a diversity of resources that may have different preprocessing requirements. Relying on multiple biomass types and sources to produce blended feedstocks can also reduce the risk to industry by diversifying reliance on any one feedstock. 


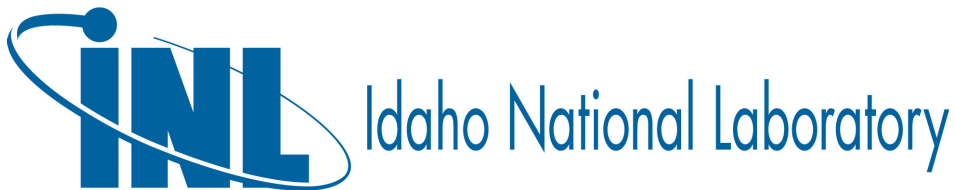

The 2020 Herbaceous SOT applies blending of multiple types of herbaceous biomass as a means of increasing access to biomass resources and meeting feedstock quality and cost specifications, which is a critical step toward feedstock commoditization. Blending refers to combining different types of biomass to consistently provide a uniform feedstock of known specifications for a conversion process at the lowest possible cost. An optimization model (Roni et al. 2019b) is used to determine least cost blend. The 2020 Herbaceous SOT incorporates two depots that are located at a distance from the biorefinery in higher-yielding counties that have significant corn stover available lower on the supply curve.

The 2020 Herbaceous SOT requires 725,000 dry tons feedstock to be delivered to the reactor throat annually. In past SOTs we have estimated farm-gate biomass availability based on yearly supply projections presented in the 2016 Billion-Ton Report (BT16) (DOE 2016b), which led to confounding of delivered cost reductions due to supply availability assumptions with cost reductions arising from BETO R\&D investment. To eliminate this problem for the 2020 Herbaceous SOT, we utilized the same supply curves used in the 2019 Herbaceous SOT (Roni et al. 2019a). This allowed a singular focus on delivered cost improvements arising from technology advancements. Moving forward in future years, we will implement use of the $\mathrm{n}^{\text {th }}$ supply scenario developed in FY19 and FY20, in conjunction with Oak Ridge National Laboratory, as a constant supply in order to focus on improvements due to BETO-funded technology improvements. Hence, in this report we also present the 2020 Herbaceous SOT recast using the supply curves and optimal depot and biorefinery locations determined for the $\mathrm{n}^{\text {th }}$ supply scenario (see Appendix B); this is presented in this report as the 2020 Herbaceous $n^{\text {th }}$ Supply SOT following presentation of the 2020 Herbaceous SOT.

\section{2020 Herbaceous Feedstock SOT}

The Biomass Logistics Model (BLM) was used to model feedstock logistics cost and energy consumption estimates for the 2020 Herbaceous Feedstock SOT design. The BLM incorporates information from a collection of databases that provide (1) engineering performance data for hundreds of equipment systems, (2) spatially explicit labor cost data sets, and (3) local tax and regulation data. The BLM's analytic engine is built in the system dynamics software package Powersim ${ }^{\mathrm{TM}}$. The BLM is designed to work with thermochemical- and biochemicalbased biofuel conversion platforms and to accommodate a range of lignocellulosic biomass types (e.g., herbaceous residues, short-rotation woody and herbaceous energy crops, woody residues, and algae). The BLM simulates the flow of biomass through the entire supply chain while tracking changes in feedstock characteristics (i.e., moisture content, dry matter, ash content, and dry bulk density) and calculating cost and energy consumption (Cafferty et al. 2013b). The energy consumption and other parameters (e.g. transportation distance, density) from BLM are also inputs to the Greenhouse Gases, Regulated Emissions, and Energy use in Transportation model (GREET 2016), to perform a cursory farm gate-to-plant gate life-cycle assessment on GHG emissions (this is completed by colleagues at Argonne National Laboratory for this report).

\subsection{Description of Logistics System Design}




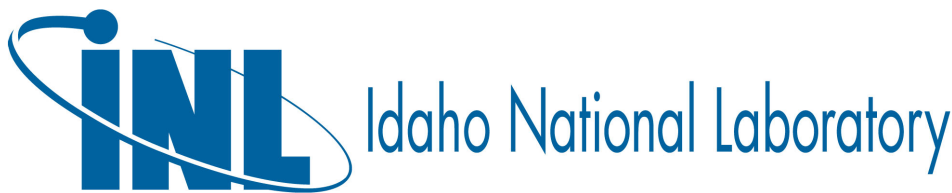

The 2020 Herbaceous SOT design assumes annual $n^{\text {th }}$-plant delivery of 725,000 dry tons of herbaceous feedstock, with biochemical conversion in-feed feedstock compositional specifications presented in Table 1 (Davis et al. 2013). The shaded rows in Table 1 show the compositional specifications for the feedstock, namely, 59\% carbohydrates, $\leq 5 \%$ ash, and $20 \%$ moisture. An additional specification is $1 / 4$ "-minus particle size at the pretreatment reactor throat.

Table 1. Delivered feedstock composition assumptions for dilute-acid pretreatment and enzymatic hydrolysis to sugars followed by biological conversion of sugars to hydrocarbons pathway (Humbird et al. 2011, Davis et al. 2013).

\begin{tabular}{lc}
\hline Component & $\begin{array}{c}\text { Composition } \\
\text { (dry wt. \%) }\end{array}$ \\
\hline Glucan & 35.05 \\
\hline Xylan & 19.53 \\
\hline Lignin & 15.76 \\
\hline Ash & 4.93 \\
\hline Acetate & 1.81 \\
\hline Protein & 3.10 \\
\hline Extractives & 14.65 \\
\hline Arabinan & 2.38 \\
\hline Galactan & 1.43 \\
\hline Mannan & 0.60 \\
\hline Sucrose & 0.77 \\
\hline Total structural carbohydrate & $\mathbf{5 8 . 9 9}$ \\
\hline Total structural carbohydrate + sucrose & $\mathbf{5 9 . 7 6}$ \\
\hline Moisture (bulk wt.\%) & $\mathbf{2 0 . 0}$ \\
\hline
\end{tabular}

The 2020 Herbaceous SOT is reported in $2016 \$$ and includes grower payment, logistics costs, and ash and moisture dockages to reflect a modeled net delivered feedstock supply cost. The modeled logistics system for the 2020 Herbaceous SOT delivers 725,000 dry tons of a $29.63 \%$ three-pass corn stover $-70.37 \%$ two-pass corn stover blend, utilizing the harvest, collection and transportation system described in the 2019 Herbaceous SOT report (Roni et al., 2019a) and summarized in Appendix A. The 2020 Herbaceous SOT also incorporates an actively managed storage system comprised of a combination of best management practices and "farm-scale technologies" such as enhanced in-storage drying to achieve storage stability objectives for early-harvested wet bales and predicts a modeled delivered feedstock cost of $\$ 80.10$ /dry ton (2016\$); this is a $\$ 1.27$ /dry ton decrease from the 2019 Herbaceous SOT.

\subsubsection{Resource Availability}

The geographic area for the 2020 Herbaceous SOT is northwestern Kansas, with the biorefinery located in Sheridan County, which is unchanged from the 2019 Herbaceous SOT. It 


\section{Idaho National Laboratory}

was assumed that all corn stover and switchgrass biomass located in Kansas, Nebraska and Colorado that could be sustainably harvested would be potentially available to meet the demand of 725,000 dry tons delivered to the pretreatment reactor throat at the biorefinery. In the 2020 Herbaceous SOT, biomass availability is assumed to be same as in the 2019 Herbaceous SOT (Roni et al. 2019a) in order to track the economic impact of technical advancements from feedstock R\&D. Biomass availability in the 2019 Herbaceous SOT was estimated by utilizing the projected 2019 supply curves from the BT16 report, modified to incorporate new (FY19) models of the impact of implementing the ILM strategy in the supply shed (completed by WBS 4.2.1.20) and of the predicted grower participation rates with the implementation of ILM (completed by WBS 1.2.1.5).

\subsubsection{Harvest and Collection}

Corn stover is the primary feedstock in the 2020 Herbaceous SOT design; while switchgrass was considered as in the 2019 Herbaceous SOT design, it was not part of the least cost design and so is not included in this report. It is assumed that corn stover is harvested by both three-pass (conventional) and two-pass methods (advanced). The three-pass corn stover harvest and collection method refers to the conventional stover harvest strategy and is also referred to as a "multi-pass harvesting system." The two-pass corn stover harvesting and collection method is an advanced, and more sustainable harvesting method, that eliminates the windrowing step (Birrell et al., 2014). Harvesting yields of three-pass corn stover and two-pass corn stover remain unchanged from the 2019 Herbaceous SOT (Roni et al., 2018), and are referenced from studies conducted by Smith and Bonner (2014).

\subsubsection{Storage}

The 2020 Herbaceous SOT incorporates an actively managed storage system comprised of a combination of best management practices and "farm-scale technologies" such as enhanced in-storage drying of high-moisture early harvested bales to achieve storage stability objectives. A newly constructed whole-bale dryer/permeameter is introduced to the storage process to dry the biomass with initial moisture content of $>30 \%$ over 30 days storage time (Figure 2). By adding the dryer, microbially-generated heat is lost at higher rates which has a negative feedback on microbial respiration rate and heat generation. The bale dryer has been shown to reduce the moisture content from $30 \%$ to $<20 \%$ and keep biodegradation and dry matter losses at $<6 \%$. Following field storage, the resulting average moisture content is assumed to be $20 \%(5 \%$ moisture loss). Both literature (Shah et al., 2011) and INL laboratory-scale storage experiments indicate that higher initial moisture content leads to greater dry matter loss; losses of individual compositional components of the biomass were estimated based on the results of INL laboratory storage experiments performed in WBS 1.2.1.1 (see Appendix A). Since the actively managed storage system will be limited to high moisture biomass, in the 2020 Herbaceous SOT design it

Figure 2. Bale dryer/bale permeameter fabricated and used by INL to measure drying, internal temperatures, and moisture loss in whole bales. Air flow is from the right to the left in the photograph. The instrumentation on the right records the temperature and relative humidity of the air entering and exiting the bale, the internal bale temperatures, and the pressure drop across the bale. The instruments on the left periodically sample the inlet and outlet gases and measure $\mathrm{CO} 2$, water vapor, and gas tracer $\left(S F_{6}\right)$, which is metered in from the silver bag at 


\section{TIIdaho National Laboratory}

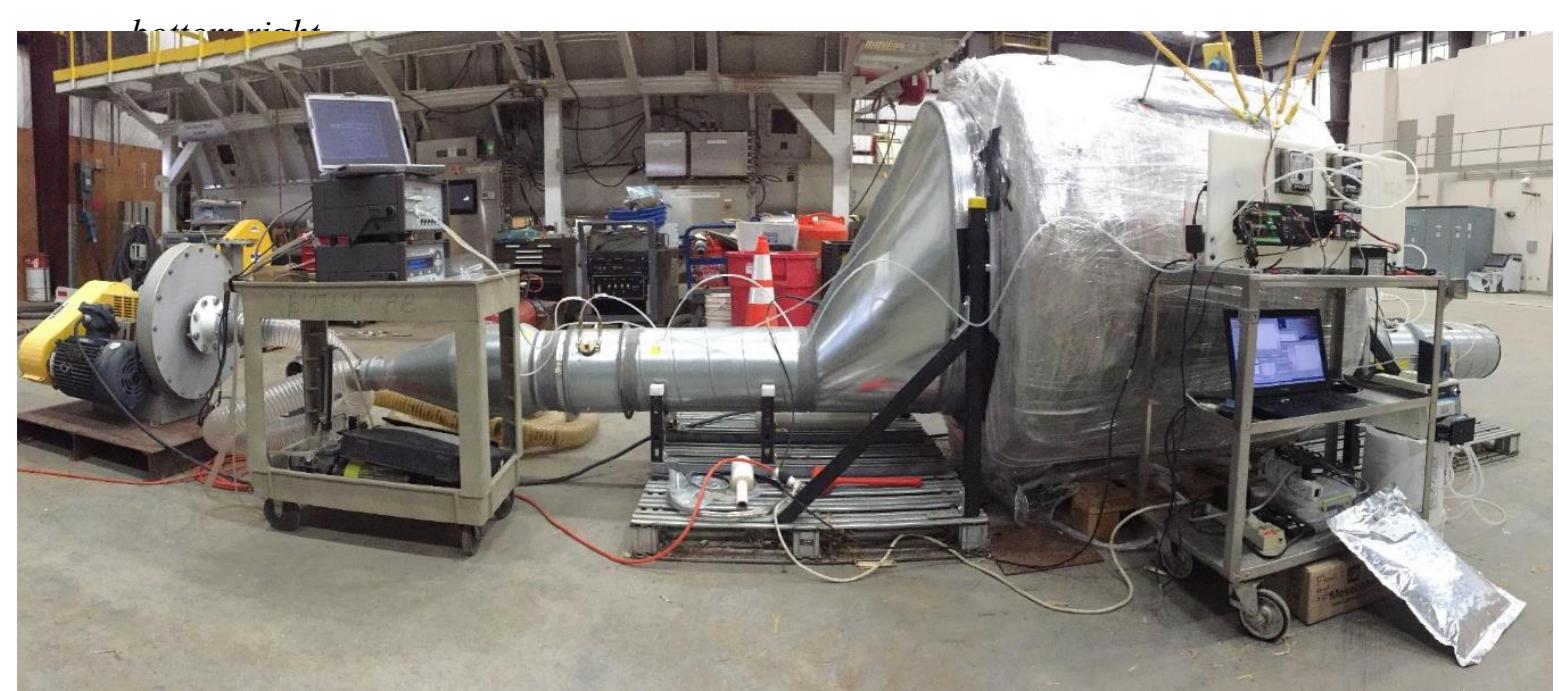

is assumed that $50 \%$ of the harvested biomass has an initial moisture content of $25 \%, 25 \%$ of the harvested biomass has an initial moisture content of $20 \%$, and the remaining $25 \%$ of the biomass has an initial moisture content of $30 \%$ (these would be the early harvested bales). With these assumptions, an average field-side stack dry matter loss of $8.88 \% /$ year was estimated for the overall corn stover storage.

\subsubsection{Preprocessing}

Feedstock preprocessing in the 2020 Herbaceous SOT design remains the same as the 2019 Herbaceous SOT design, which included size reduction, grinding and densification.

However, preprocessing operating conditions and performance were updated based on the altered biomass properties exiting from the new storage design. For example, since the biomass coming from storage will have lower moisture than in the 2019 Herbaceous SOT, the hammer mill will consume less energy. An EZ Ration Processor is used for the first stage size reduction, which is a horizontal bale processor originally designed for blending cattle feed components such as hay and corn stalks. The 3-rotating-drum debaling head design of the bale processor (Figure 3) requires lower rpm and energy and eliminates the slugging flow observed in the first stage hammer mill usen in SOTs prior to 2019. Moreover, the EZ Ration bale processor can feed the two bales at separate feed rates (this feature was originally developed by the manufacturer for the cattle feed blending function). This could be an advantage for blending bales with different moisture contents to mitigate very wet bales, or for blending bales of different biomass types. Pilot-scale testing was performed during FY20 in the Biomass Feedstock User Facility (BFNUF) at INL (WBS 1.2.3.3) to collect the parametric data for preprocessing. 


\section{SII Idoho National laboridory}

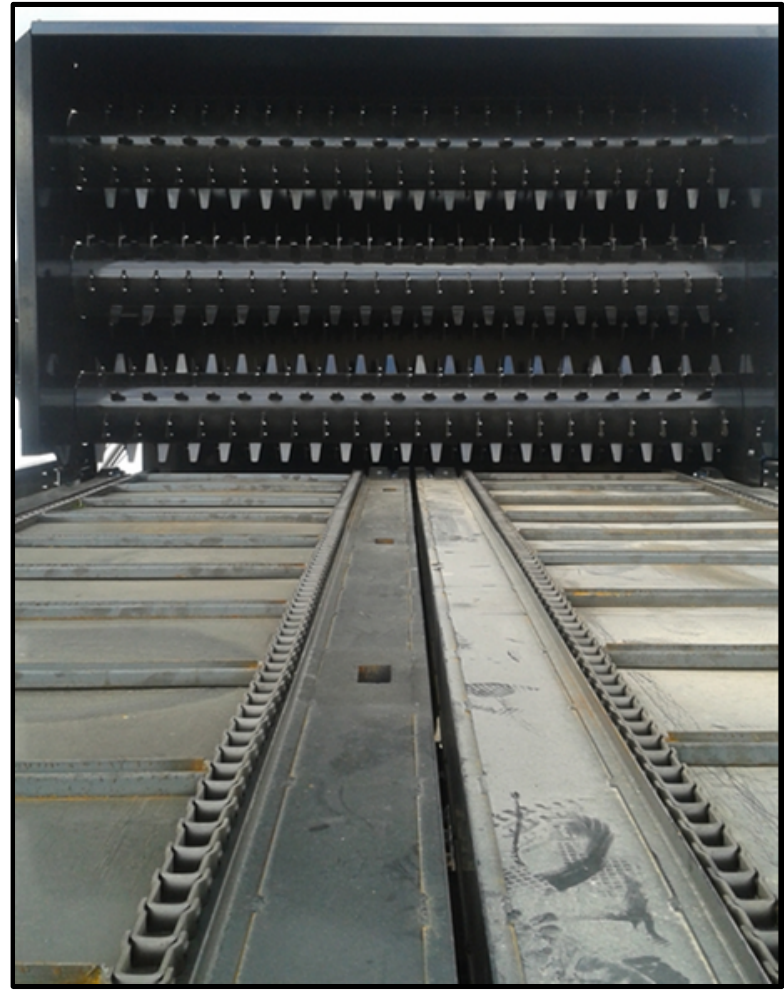

Figure 3. EZ Ration Debaling System.

\subsubsection{Transportation and Handling}

Transportation and handling include all steps involved in the movement of biomass from multiple local locations to a centralized location (such as a preprocessing facility or biomass depot), including loading, trucking, and unloading. Feedstock transportation in the 2020 Herbaceous SOT includes both bale and pellet transportation, which are described in the 2019 Herbaceous SOT (Roni et al., 2019a) and shown in Appendix A. In bale transportation, biomass bales are loaded onto semi-trucks after the field side storage, transported, and unloaded at the depots. After pelleting, biomass pellets are then loaded and transported to the biorefinery.

\subsubsection{Cost Summary and Energy Usage}

Results of the supply chain analysis are summarized in Table 2, which provides the detailed cost breakdown and greenhouse gas emissions. The greenhouse gas emissions analysis was completed by Argonne National Laboratory (ANL), using energy consumption and transportation distance data from the BLM. ANL employed the Greenhouse Gases, Regulated Emissions, and Energy use in Transportation model (GREET ${ }^{\circledR}$ ) (Argonne National Laboratory, 2017) to conduct detailed life-cycle analysis of farm gate-to-biorefinery gate GHG emissions of the herbaceous biomass scenarios presented in this report. 
Table 1. The 2020 Herbaceous SOT modeled cost and GHG estimates for an herbaceous feedstock supply system supplying 725,000 dry tons annually in northwestern Kansas. Design details are provided in Appendix A.

\begin{tabular}{lcccc}
\hline \multirow{2}{*}{ Cost Element } & \multicolumn{4}{c}{ Cost (\$/dry ton) } \\
\cline { 2 - 5 } & $\begin{array}{c}\text { Three-Pass } \\
\text { Stover }\end{array}$ & $\begin{array}{c}\text { Two-Pass } \\
\text { Stover }\end{array}$ & $\begin{array}{c}\text { Least-Cost } \\
\text { Blend }^{\mathbf{b}}\end{array}$ & $\begin{array}{c}\text { GHG emissions } \\
\text { (kg CO }_{2} \mathbf{e} / \text { ton) }\end{array}$ \\
\hline Blend Ratio & $29.63 \%$ & $70.37 \%$ & $100.00 \%$ & \\
\hline Grower payment & $\$ 21.71$ & $\$ 20.16$ & $\$ 20.62$ & \\
\hline Harvest and collection & $\$ 13.84$ & $\$ 18.79$ & $\$ 17.33$ & 11.17 \\
\hline Storage and queuing & $\$ 6.66$ & $\$ 6.74$ & $\$ 6.72$ & 2.50 \\
\hline Transportation and handling & $\$ 13.74$ & $\$ 14.97$ & $\$ 14.61$ & 16.60 \\
\hline In-plant receiving and preprocessing & $\$ 19.43$ & $\$ 19.43$ & $\$ 19.43$ & 47.21 \\
\hline Dockage & $\$ 2.59$ & $\$ 0.89$ & $\$ 1.39$ & \\
\hline Total & $\mathbf{\$ 7 7 . 9 7}$ & $\mathbf{\$ 8 0 . 9 8}$ & $\mathbf{\$ 8 0 . 1 0}$ & $\mathbf{7 7 . 4 8}$ \\
\hline
\end{tabular}

a Pesticide and fertilizer emissions incurred during biomass production were attributed to the biomass growth stage of the life cycle and are not included.

$\mathrm{b}$ The blend costs are presented as the weighted average of the blend component costs.

c Grower payment taken as the cost assumed for procurement of grass clippings.

Table 3 shows the modeled cost estimates for the herbaceous feedstock supply system for the 2019 SOT, 2020 SOT and the 2022 Projection. The small increase of $\$ 0.06 /$ dry ton in grower payment from the 2019 Herbaceous SOT is a result of increasing the proportion of two-pass corn

Table 3. Summary of modeled cost estimates for the herbaceous feedstock supply system for biochemical conversion pathway for the 2019 SOT, 2020 SOT and 2022 Projection.

\begin{tabular}{lccc}
\hline & $\begin{array}{c}\mathbf{2 0 1 9} \\
\text { SOT }\end{array}$ & $\begin{array}{c}\mathbf{2 0 2 0} \\
\text { SOT }\end{array}$ & $\begin{array}{c}\mathbf{2 0 2 2} \\
\text { Projection }\end{array}$ \\
\hline Feedstock & Blend & Blend & Blend \\
\hline Net delivered cost (\$/dry ton) & $\mathbf{\$ 8 1 . 3 7}$ & $\mathbf{\$ 8 0 . 1 0}$ & $\mathbf{\$ 7 9 . 0 7}$ \\
\hline Grower payment (\$/dry ton) & $\$ 20.56$ & $\$ 20.62$ & $\$ 22.37$ \\
\hline Feedstock logistics (\$/dry ton) & $\mathbf{\$ 6 0 . 8 1}$ & $\mathbf{\$ 5 9 . 4 7}$ & $\mathbf{\$ 5 6 . 7 0}$ \\
\hline Harvest \& collection (\$/dry ton) & $\$ 17.14$ & $\$ 17.33$ & $\$ 12.79$ \\
\hline Storage \& queuing (\$/dry ton) & $\$ 6.49$ & $\$ 6.72$ & $\$ 8.35$ \\
\hline Preprocessing (\$/dry ton) & $\$ 20.84$ & $\$ 19.43$ & $\$ 21.44$ \\
\hline Transportation \& handling (\$/dry ton) & $\$ 14.76$ & $\$ 14.61$ & $\$ 12.44$ \\
\hline Dockage (\$/dry ton) & $\$ 1.58$ & $\$ 1.39$ & $\$ 1.68$ \\
\hline
\end{tabular}




\section{Idaho National Laboratory}

stover in the blend. The $\$ 0.19 /$ dry ton increase in harvest and collection costs from 2019 results from the higher harvesting cost of two-pass corn stover, which is the largest component of the blend and is required to meet the carbohydrate specification.

In the 2020 Herbaceous SOT, a commercial grain dryer blower was included the field storage for early harvested bales, which allowed the overall average stack moisture content to decrease from $25 \%$ to $20 \%$, and reduce dry matter loss from $12 \%$ to a weighted estimate of $8.88 \%$ compared to the 2019 Herbaceous SOT. Hence, there was $\$ 0.23 /$ dry ton increase in feedstock in storage cost in the 2019 SOT. The $\$ 1.41$ dry ton reduction in preprocessing is a composite result of increased performance in the hammer mill due to the lower moisture coming from storage. Due to the lower moisture exiting storage and to the reduction in total transported biomass (due to reduced dry matter loss), the total transportation cost was reduced by $\$ 0.15 /$ dry ton. The decrease of $\$ 0.19 /$ dry ton in dockage is attributed to the increased amount of lower ash two-pass corn stover in the blend (note that dockage is included in the optimization as a cost component). A greenhouse gas emissions (GHG) assessment was completed by Argonne National Laboratory using the 2020 Greenhouse Gases, Regulated Emissions, and Energy use in Transportation model (GREET), estimating a decrease of up to $6.68 \mathrm{~kg} \mathrm{CO}_{2} \mathrm{e} /$ ton from the 2019 SOT $\left(84.16 \mathrm{~kg} \mathrm{CO}_{2} \mathrm{e} /\right.$ ton in the $2019 \mathrm{SOT}$ to $77.48 \mathrm{~kg} \mathrm{CO}_{2} \mathrm{e} /$ ton in the 2020 Herbaceous Feedstock SOT). This net reduction is attributed to reduced energy consumption in the hammer mill, reduced high emission feedstock used in the blend (less three-pass corn stover), and incorporation of the updated GREET model.

As stated above, the least-cost blend for this analysis consisted of $29.63 \%$ three-pass corn stover and $70.37 \%$ two-pass corn stover. The amounts of harvested biomass (prior to storage) required to produce this blend are shown in Table 4, along with their carbohydrate and ash compositions and individual delivered costs. The depot locations, biomass source counties and biorefinery location are listed in Table 5 and Table 6 and are shown pictorially in Figure 4 . The least cost supply chain network utilized two distributed depots (Nodes 23 and 25 in Figure 4) for a biorefinery located in Sheridan County, Kansas. To avoid exceeding the capacity of depot at Node 25, a small portion of the two-pass corn stover purchased from Node 18 is distributed to the depot at Node 23 . The results also show that a biorefinery with a design capacity of 725,000 dry tons/year, would need to procure at least 811,180 dry tons of biomass annually to account for losses in the system. This procured biomass is 29,487 dry tons less than the 2019 Herbaceous SOT. 
Table 4. Delivered (reactor-throat) costs and compositions of the herbaceous biomass sources, the preprocessed blendstocks produced from these biomass sources, and the least-cost blend. The modeled cost estimates are for delivery of 725,000 dry tons/year of blended feedstock at $59.00 \%$ carbohydrate, $8.63 \%$ ash and $11.41 \%$ moisture, and are discussed in detail in Appendix A. An ash dockage of \$1.37/dry ton and a moisture dockage of \$0.03/dry ton are included in the total delivered blend cost. All costs are in $2016 \$$.

\begin{tabular}{|c|c|c|c|c|c|}
\hline \multirow{2}{*}{ Biomass Type } & \multirow{2}{*}{$\begin{array}{c}\text { Raw } \\
\text { Biomass } \\
\text { Purchased } \\
\text { (dry tons) }\end{array}$} & \multirow{2}{*}{$\begin{array}{c}\begin{array}{c}\text { Pelleted } \\
\text { Blendstocks }\end{array} \\
\text { Produced } \\
\text { (dry tons) }\end{array}$} & \multicolumn{3}{|c|}{ Pelleted Blendstocks } \\
\hline & & & $\begin{array}{c}\text { Total } \\
\text { Carbohydrates } \\
\text { (wt\% db) }\end{array}$ & $\begin{array}{c}\text { Ash } \\
(w t \% \\
\text { db) }\end{array}$ & $\begin{array}{l}\text { Delivered Cost } \\
\text { (\$/dry ton) }\end{array}$ \\
\hline Three-pass corn stover & 240,350 & 214,815 & $57.10 \%$ & $11.80 \%$ & $\$ 77.97$ \\
\hline Two-pass corn stover & 570,830 & 510,185 & $59.80 \%$ & $7.30 \%$ & $\$ 80.98$ \\
\hline Totals & 811,180 & 725,000 & $59.00 \%$ & $8.63 \%$ & $\$ 80.10$ \\
\hline
\end{tabular}

Table 5. Node IDs and county names for the biomass source counties for the supply system depicted in Figure 3. The depot counties (modes 23 and 25) are also farm-gate biomass source counties.

\begin{tabular}{clcl}
\hline Node & \multicolumn{1}{c}{ County } & Node & \multicolumn{1}{c}{ County } \\
\hline- & Sheridan County, KS & 15 & Frontier County, NE \\
\hline 1 & Custer County, NE & 16 & Gosper County, NE \\
\hline 2 & Valley County, NE & 17 & Phelps County, NE \\
\hline 3 & Greeley County, NE & 18 & Kearney County, NE \\
\hline 4 & Nance County, NE & 19 & Adams County, NE \\
\hline 5 & Sherman County, NE & 20 & Clay County, NE \\
\hline 6 & Howard County, NE & 21 & Fillmore County, NE \\
\hline 7 & Merrick County, NE & 22 & Dundy County, NE \\
\hline 8 & Dawson County, NE & 23 & Red Willow County, NE \\
\hline 9 & Buffalo County, NE & 24 & Furnas County, NE \\
\hline 10 & Hall County, NE & 25 & Harlan County, NE \\
\hline 11 & Hamilton County, NE & 26 & Franklin County, NE \\
\hline 12 & York County, NE & 27 & Webster County, NE \\
\hline 13 & Chase County, NE & 28 & Nuckolls County, NE \\
\hline 14 & Hayes County, NE & 29 & Thayer County, NE \\
\hline
\end{tabular}

Table 6. Optimal locations and sizes of distributed depots for least cost delivery of 725,000 dry tons/year of blended feedstock to Sheridan County, KS. Nodes are identified by county name in Table 5 and are shown geographically in Figure 3. 


\section{SiV Idaho Nationdl laboratory}

\begin{tabular}{|c|c|c|c|c|c|}
\hline Node & Identifier & County & $\begin{array}{c}\text { Capacity } \\
\text { (dry tons/yr) }\end{array}$ & Biomass Type & $\begin{array}{l}\text { Biomass } \\
\text { Source } \\
\text { Nodes } \\
\end{array}$ \\
\hline- & Biorefinery & Sheridan, KS & 725,000 & Blend & 23,25 \\
\hline \multirow{2}{*}{23} & \multirow{2}{*}{ Depot } & \multirow{2}{*}{ Red Willow, NE } & \multirow{2}{*}{162,169} & $\begin{array}{l}\text { three-pass } \\
\text { corn stover }\end{array}$ & $\begin{array}{l}8,13,14,15, \\
16,22,23,24 \\
\end{array}$ \\
\hline & & & & $\begin{array}{l}\text { two-pass } \\
\text { corn stover }\end{array}$ & 18 \\
\hline \multirow[b]{2}{*}{25} & \multirow[b]{2}{*}{ Depot } & \multirow[b]{2}{*}{ Harlan, NE } & \multirow[b]{2}{*}{562,831} & $\begin{array}{l}\text { three-pass } \\
\text { corn stover }\end{array}$ & $9,16,19,27$ \\
\hline & & & & $\begin{array}{l}\text { two-pass } \\
\text { corn stover }\end{array}$ & $\begin{array}{c}1,2,3,4,5,6, \\
7,10,11,12, \\
17,20,21,25, \\
26,28,29\end{array}$ \\
\hline
\end{tabular}

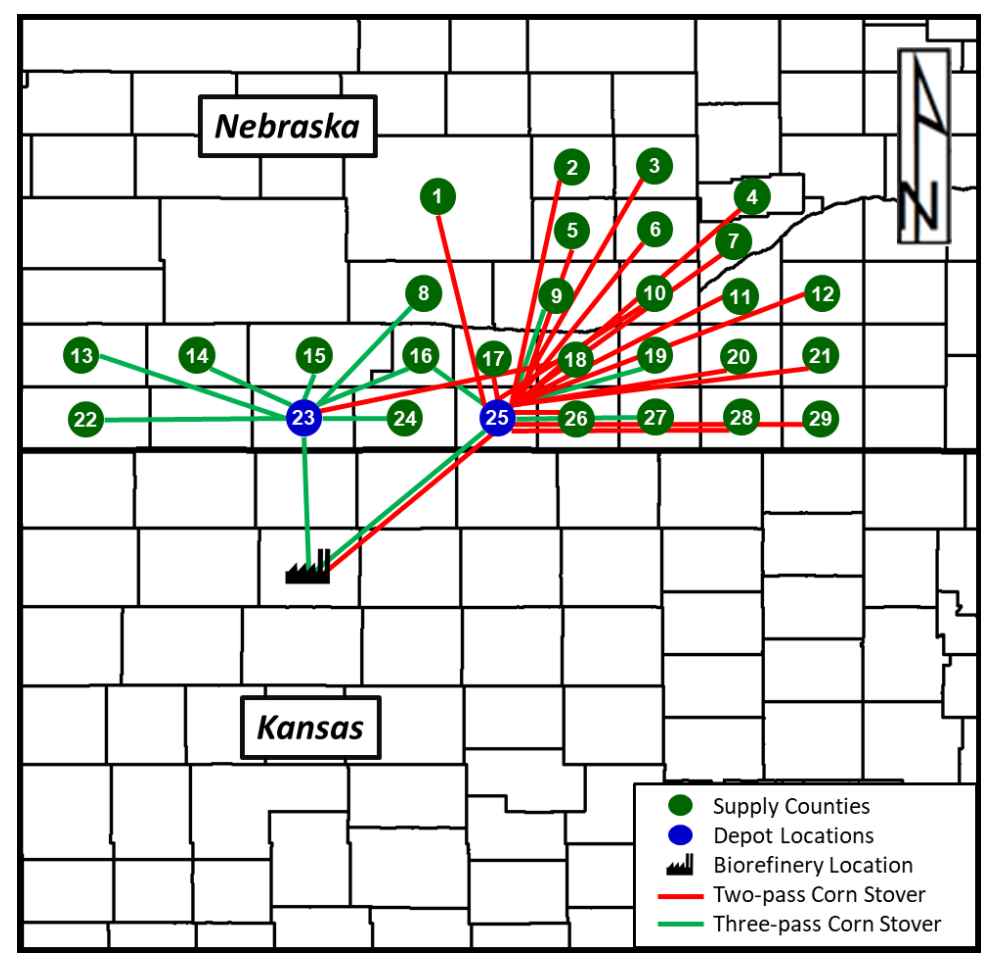

Figure 4. Supply chain network design for the 2020 Herbaceous SOT. The supply chain has 2 distributed depots (Nodes $=23$ and 25) with the biorefinery located in Sheridan County, Kansas. Threepass corn stover is sourced from Nodes 8, 9, 13, 14, 15, 16, 19, 22, 23, 24 and 27. Two-pass corn stover is sourced from Nodes 1, 2, 3, 4, 5, 6, 7, 10, 11, 12, 17, 18, 20, 21, 25, 26, 28 and 29. County names are shown with their node identifiers in Table 5 and Table 6. 


\section{i

\subsubsection{Sensitivity Analysis of Costs}

Sensitivity analysis was performed on the delivered feedstock cost for the 2020 Herbaceous SOT. Critical process parameters were investigated to determine the impact of uncertainty in their values on the delivered feedstock cost. The parameters varied in the sensitivity analysis are shown in Table 7.

Table 7. Model parameters varied for the sensitivity analysis. Each parameter was varied independently based on actual variations observed in experimental and field data.

\begin{tabular}{|c|c|c|c|c|c|}
\hline Parameter & Units & Biomass Type & Minimum & $\begin{array}{l}\text { Average } \\
\text { (SOT) }\end{array}$ & Maximum \\
\hline \multirow{2}{*}{$\begin{array}{l}\text { Effective } \\
\text { windrowing rate }\end{array}$} & \multirow{2}{*}{ acres/hr } & Three-pass corn stover & 10.78 & 11.5 & 12.51 \\
\hline & & Two-pass corn stover & n.a. & n.a. & n.a. \\
\hline \multirow{2}{*}{$\begin{array}{l}\text { Effective baling } \\
\text { rate }^{\mathrm{b}}\end{array}$} & \multirow{2}{*}{ dry ton $/ \mathrm{hr}$} & Three-pass corn stover & 16.14 & 26.18 & 28.10 \\
\hline & & Two-pass corn stover & 8.88 & 14.4 & 24.7 \\
\hline $\begin{array}{l}\text { Field side storage } \\
\text { dry matter loss }{ }^{\mathrm{c}}\end{array}$ & $\%$ & $\begin{array}{l}\text { Three-pass corn stover } \\
\text { and Two-pass corn stover }\end{array}$ & $5.58 \%$ & $8.88 \%$ & $14.21 \%$ \\
\hline $\begin{array}{l}\text { Bale transport } \\
\text { loading/unloading } \\
\text { time }^{\mathrm{d}}\end{array}$ & minutes & $\begin{array}{l}\text { Three-pass corn stover } \\
\text { and Two-pass corn stover }\end{array}$ & 39 & 42 & 45 \\
\hline Bale density ${ }^{e}$ & $\mathrm{lb} / \mathrm{ft}^{3}$ & $\begin{array}{l}\text { Three-pass corn stover and } \\
\text { Two-pass corn stover }\end{array}$ & 11 & 12 & 13 \\
\hline $\begin{array}{l}\text { Hammer mill } \\
\text { effective } \\
\text { throughput }^{\mathrm{f}}\end{array}$ & $\begin{array}{l}\text { dry tons } / \mathrm{hr} / \\
\text { machine }\end{array}$ & $\begin{array}{l}\text { Three-pass corn stover and } \\
\text { Two-pass corn stover }\end{array}$ & 2.61 & 2.92 & 3.24 \\
\hline $\begin{array}{l}\text { Hammer mill } \\
\text { effective energy } \\
\text { consumption }^{\mathrm{f}}\end{array}$ & $\mathrm{kWh} / \mathrm{dry}$ ton & $\begin{array}{l}\text { Three-pass corn stover and } \\
\text { Two-pass corn stover }\end{array}$ & 28.0 & 35.0 & 42.0 \\
\hline $\begin{array}{l}\text { Bale processor } \\
\text { throughput }^{\mathrm{f}}\end{array}$ & $\begin{array}{c}\text { dry } \\
\text { tons } / \text { hr/machine }\end{array}$ & $\begin{array}{l}\text { Three-pass corn stover and } \\
\text { Two-pass corn stover }\end{array}$ & 5 & 10 & 13 \\
\hline $\begin{array}{l}\text { Bale processor } \\
\text { energy } \\
\text { consumption }^{\mathrm{f}}\end{array}$ & $\mathrm{kWh} / \mathrm{dry}$ ton & $\begin{array}{l}\text { Three-pass corn stover and } \\
\text { Two-pass corn stover }\end{array}$ & 6.5 & 8.0 & 11.0 \\
\hline $\begin{array}{l}\text { Pelleting } \\
\text { throughput }^{\mathrm{f}}\end{array}$ & $\begin{array}{l}\text { dry tons } / \mathrm{hr} / \\
\text { machine }\end{array}$ & $\begin{array}{l}\text { Three-pass corn stover and } \\
\text { Two-pass corn stover }\end{array}$ & 3.43 & 3.62 & 3.76 \\
\hline $\begin{array}{l}\text { Pelleting energy } \\
\text { consumption }\end{array}$ & $\mathrm{kWh} / \mathrm{dry}$ ton & $\begin{array}{l}\text { Three-pass corn stover and } \\
\text { Two-pass corn stover }\end{array}$ & 33.79 & 32.49 & 34.68 \\
\hline
\end{tabular}


Table 7. (continued)

\begin{tabular}{|c|c|c|c|c|c|}
\hline Parameter & Units & Biomass Type & $\begin{array}{l}\text { Minimum } \\
\text { (SOT) }\end{array}$ & $\begin{array}{l}\text { Average } \\
\text { (SOT) }\end{array}$ & $\begin{array}{l}\text { Maximum } \\
\quad(\text { SOT) }\end{array}$ \\
\hline $\begin{array}{l}\text { Bypass during } \\
\text { fractional milling }\end{array}$ & $\%$ & $\begin{array}{l}\text { Three-pass corn stover and } \\
\text { Two-pass corn stover }\end{array}$ & 26.0 & 30.0 & 32.7 \\
\hline Interest rate ${ }^{\mathrm{h}}$ & $\%$ & $\begin{array}{l}\text { Three-pass corn stover and } \\
\text { Two-pass corn stover }\end{array}$ & 4.0 & 8.0 & 12.0 \\
\hline
\end{tabular}

a: Effective windrowing rate is variated based on variation of field efficiency measured from time series data (Roni et al., 2018).

b: Depends on variation of yield and equipment capacity. Empirical field data from DOE co-sponsored Biomass Alliance for Logistics Efficiency and Specifications (BALES) project (Comer, 2017) and DOE-sponsored "Growing Bioeconomy Markets: Farm-to-Fuel in Southside Virginia" project.(DOE.,2017).were utilized to measure the variation in two-pass corn stover and switchgrass .The variation in three-pass corn stover was estimated by normalizing the two-pass corn stover data by applying actual baling rate during three-pass corn stover baling.

c: Assumed based on observed variation during storage

$\mathrm{d}$ : Bale load time variation is measured from variation of bale loads by Stinger ALSS (STINGER,2015).

e: Variation is measured based on empirical data from DOE funded integrated landscape design project (Roni et al., 2018).

f: INL PDU data and Forest Concepts data were utilized to measure the variation in throughput and energy consumption under base case process conditions (e.g. moisture, screen size) for corn stover and switchgrass. Switchgrass percentage variation of throughput and energy consumption from base case is utilized to estimate the grass clippings variations

$\mathrm{g}$ : INL PDU data were utilized to measure the variation in percentage of material by bypassed during second stage grinding under base case process conditions (e.g. moisture, screen size) for corn stover and switchgrass

$\mathrm{h}$ : Assumptions based on expected variations

Figure 5 shows the results of the sensitivity analysis; delivered cost was found to vary from $\$ 77.12-\$ 85.36 /$ dry ton $(2016 \$$ ). The top five factors impacting uncertainty in the delivered cost included baling rate, interest rate, bale density, storage dry matter loss, and bale processor throughput; all of these except for interest rate are prior or current FT-funded R\&D topics. Based on the observed variation, baling throughput is a key contributor to uncertainty, with its maximum value reducing the delivered feedstock by $\$ 2.98 /$ dry ton, whereas its minimum value would increase the delivered feedstock cost by $\$ 5.26 /$ dry ton. Additional parameters that had measurable effects on the uncertainty in delivered feedstock price included bale density, storage dry matter loss, and bale processor throughput. Uncertainties in interest rate, led to delivered cost ranges of $-\$ 1.56 /$ dry ton to $+\$ 1.51 /$ dry ton.

Figure 5. Tornado chart showing sensitivity of cost to operational parameters used to model the 2020 Herbaceous SOT Design. Values in the parenthesis represent the minimum, SOT and maximum value of each parameter for the different biomass sources. 


\section{INDUSTRIAL RELEVANCE OF THE BLENDSTOCKS}

The availability of a biomass resource is not static, nor does it have a single definition. For the purposes of this report, availability is defined as the quantity of biomass materials that can be mobilized into the supply chain at a price that meets current cost targets. More specifically, resource availability assumed in this report is the quantity of three-pass and twopass corn stover that can be purchased at average grower payments of $\$ 21.71$ /dry ton and $\$ 20.16 /$ dry ton, respectively. The current availability of the blendstocks has been primarily determined through use of the 2016 Billion Ton Report. While BT16 primarily presents projections of how the market will develop based on sustained investment and technology improvement, the 2016 estimates in BT16 represented the currently economically available resources in the calendar year 2016. In 2016 it was estimated that there were 114,072,663 dry tons of corn stover available nationally, with 1,095,021 dry tons of corn stover within 100 miles of the study area. The region of interest for the 2020 herbaceous SOT remains the same as the 2019 SOTs, with the assumed biorefinery location in Sheridan County, KS. Northwest Kansas was chosen to demonstrate the barriers and cost of operating outside the niche, high-yield areas, which are more representative of yield conditions encountered when operating a national-scale bioenergy industry. However, the feedstock properties that are important to the conversion process, (i.e. ash, moisture, and carbohydrate content) were conservatively assumed to maintain applicability of the supply chain operations at a national scale.

\section{QUALIFICATION OF THE BLENDSTOCKS FOR RENEWABLE IDENTIFICATION NUMBERS}

The Environmental Protection Agency revised the National Renewable Fuel Standard Program to implement the requirements of the Energy Security and Independence Act of 2007 (EISA), in 2010. The revision of the program became known as RFS2 and mandated the use of 36 billion gallons of renewable fuel by 2022. As part of the revised rules, definitions of qualified biofuel feedstocks were outlined; the revised rules stipulated that "renewable fuels" had to be made from materials that qualify as renewable biomass. To be considered renewable biomass the materials must conform to the specified types and land types from where they are harvested as directed by EISA. From the final rule published in Vol 75, No. 58 of the Federal Register on page 14681 .

\section{"The definition includes:}

Planted crops and crop residue from agricultural land cleared prior to December 19, 2007 and actively managed or fallow on that date.

$\square$ Planted trees and tree residue from tree plantations cleared prior to December 19, 2007 and actively managed on that date.

$\square$ Animal waste material and byproducts.

$\square$ Slash and pre-commercial thinnings from non-federal forestlands that are neither oldgrowth nor listed as critically imperiled or rare by a State Natural Heritage program. Biomass cleared from the vicinity of buildings and other areas at risk of wildfire. Algae. 


\section{Idaho National Laboratory}

- Separated yard waste and food waste."

Biochemical conversion focuses primarily on herbaceous materials. Specifically, the qualification must be examined for the three potential feedstock sources that were considered: corn stover, switchgrass and grass clippings.

Corn stover qualifies as a renewable material under Section II.B.4.a.i on page 14691. This section states that “... planted crops and crop residue harvested from agricultural land cleared or cultivated at any time prior to December 19,2007, that is either actively managed or fallow, and non-forested." This section goes on to further define both planted crops and crop residue. The definition of planted crops is the following:

"All annual or perennial agricultural crops from existing agricultural land that may be used as feedstock for renewable fuel, such as grains, oilseeds, and sugarcane, as well as energy crops, such as switchgrass, prairie grass, duckweed and other species (but not including algae species or planted trees), providing that they were intentionally applied by humans to the ground, a growth medium, or a pond or tank, either by direct application as seed or plant, or through intentional natural seeding or vegetative propagation by mature plants introduced or left undisturbed for that purpose."

While crop residue is defined as the following:

"The biomass left over from the harvesting or processing of planted crops from existing agricultural land and any biomass removed from existing agricultural land that facilitates crop management (including biomass removed from such lands in relation to invasive species control or fire management), whether or not the biomass includes any portion of a crop or crop plant."

In addition to the definitions of planted crops and crop residue, the qualification as a renewable material stipulates that the biomass must be harvested from "existing agricultural land", which is limited to three land types: cropland, pastureland and Conservation Reserve Program land.

Cropland is defined for the purposes of EISA and RFS2 as, "land used for the production of crops for harvest, including cultivated cropland for row crops or close-grown crops and noncultivated cropland for horticultural crops". While pastureland is defined as, "land managed primarily for the production of indigenous or introduced forage plants for livestock grazing or hay production, and to prevent succession to other plant types." Another caveat for the qualification of agricultural land is that the land must have been cleared or cultivated prior to December 19, 2007 and actively managed or fallow and non-forested since December 19, 2007. Under normal conditions, both corn stover and switchgrass will meet the conditions necessary to be deemed a renewable material and qualify for RINS.

Ultimately, the qualification of biomass as renewable is subject to verification that the feedstocks meet the requirements specified by EISA. Currently, there are three mechanisms that provide this verification. First, the individual fuel production facilities can perform their own recordkeeping and reporting. Second, renewable fuel producers can form a consortium that funds 


\section{Idaho National laboratory}

third-party audit of quality assurance, based on an EPA approved plan. The final method only is only available to producers sourcing their biomass entirely from within the United States. This method uses an aggregate compliance approach using USDA publicly available data about agricultural land to form the basis of determination on feedstock renewability. In the case of non-agricultural products, producers must obtain enough documentation from their suppliers to prove compliance with EISA definitions.

\section{2020 Herbaceous $\mathbf{n}^{\text {th }}-$ Supply SOT}

As discussed above, in past SOTs we estimated farm-gate biomass availability based on yearly supply projections presented in the 2016 Billion-Ton Report (BT16) (DOE 2016b). This led to confounding of delivered cost reductions due to supply availability assumptions with cost reductions arising from BETO R\&D investment. To eliminate this problem for the 2020 Herbaceous SOT presented above, we utilized the same supply curves used in the 2019 Herbaceous SOT (Roni et al. 2019a). In this section, we recast the 2020 Herbaceous SOT to utilize fixed $\mathrm{n}^{\text {th }}$-supply scenario supply curves for National and regional supplies of corn stover and switchgrass that will be used in all future Herbaceous SOTs. We refer to this recast SOT as the 2020 Herbaceous $n^{\text {th }}$-Supply SOT.

The $\mathrm{n}^{\text {th }}$-supply scenario was developed from a series of analyses developed jointly with ORNL (see Appendix B) and predicts optimal depot and biorefinery sites for corn stover and switchgrass supply in a demand-based supply in 2040. One impact of recasting the 2020 Herbaceous SOT to the $\mathrm{n}^{\text {th }}$-supply scenario is thus altering depot locations (and sizes) to align with the demand-based supply. For future SOTs these will remain fixed, allowing the SOTs to focus solely on the cost and quality impacts of BETO-funded technology advancements.

\subsection{Resource Availability}

Addressing biomass cost and quality targets is important to achieve the 2022 feedstock cost projection. Many of the targets are assumed to be for an $\mathrm{n}^{\text {th }}$-Plant (future) biorefinery, but feedstock cost and availability assumptions are based on present time projections of potential feedstock availability. To ensure consistency in analyses, analysts at INL and ORNL have defined a set of supply chain assumptions for an $\mathrm{n}^{\text {th }}$-Supply scenario and generated an updated resource availability for corn stover and switchgrass biomass feedstocks to supply $\mathrm{n}^{\text {th }}$-Plant biorefineries. A modified version of INL's Least-Cost Formulation model was developed to perform the analysis. A Mixed Integer Linear Programming (MILP) Model was used to locate 263 depot locations nationwide with delivered feedstock costs (corn stover and switchgrass) at less than $\$ 79.07 /$ dry ton $(2016 \$)$ using corn stover and switchgrass biomass available in 2040 from BT16. The sited depot locations were used as inputs to the POLYSYS model to generate updated biomass availability maps (POLYSYS demand runs); biomass availability and depot/biorefinery locations used in this case are based on these POLYSYS demand runs. In the POLYSYS demand runs, the minimum grower payment for corn stover was set at $\$ 30 /$ dry ton based on the assumption that having existing depots in place would increase biomass demand 
and thus reduce grower payments. Since this assumption is inconsistent with grower payment assumptions (minimum of $\$ 40 /$ dry ton) that were used to develop delivered cost targets for the 2022 Projection and the 2030 Design, we used \$40/dry ton as the minimum farm gate cost for corn stover (switchgrass remained unchanged). The assumptions, modelling approach and key results for the POLYSYS demand run are reproduced in Appendix B, as at the time of this writing they have not yet been published in the public domain in manuscript or external report form.

Logistic costs were estimated for the two potential depot locations (locations 550 and 551 shown in Figure 5) that are closest to Sheridan County in northwestern Kansas. The results showed that the minimized logistic cost for the two locations were similar, therefore, the geographic biorefinery location for the $2020 \mathrm{n}^{\text {th }}$-Supply SOT case remains as Sheridan County, Kansas, which is unchanged from the 2019 Herbaceous SOT. It was assumed that all the biomass located in Kansas, Nebraska and Colorado would be potentially available to meet the demand of 725,000 dry tons delivered to the pretreatment reactor throat at the biorefinery. 

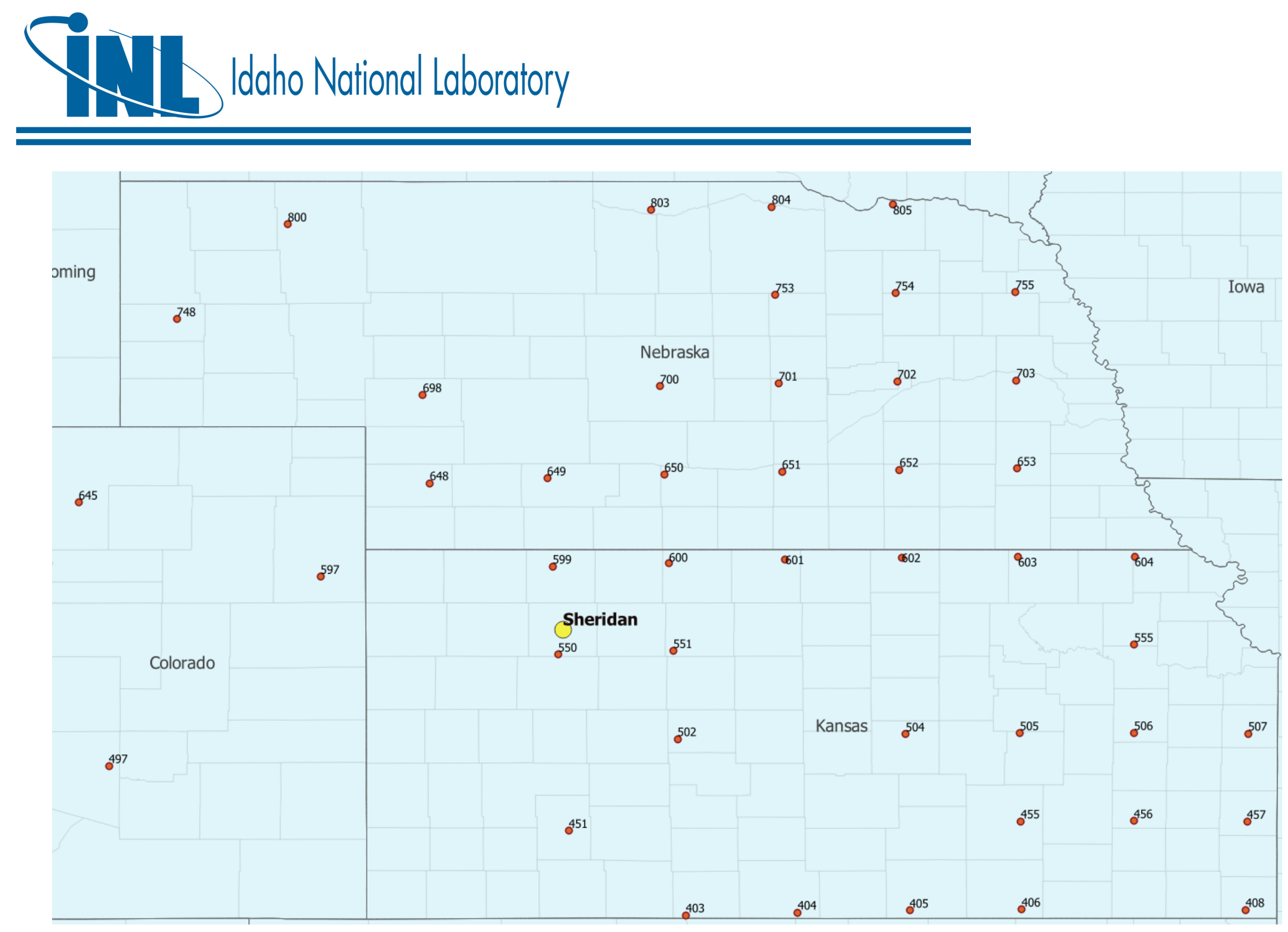

Figure 5. The geographic area for the 2020 Herbaceous $n^{\text {th }}$-Supply SOT. The red circles indicate potential depot locations that are used for the POLYSYS demand run. Location 550 is set as the biorefinery location for the 2020 Herbaceous $n^{\text {th }}$-Supply SOT. 


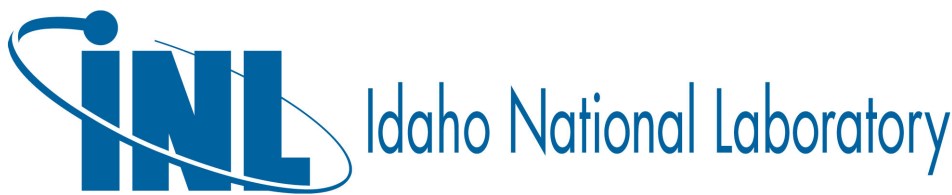

\subsection{Logistics Costs}

Results of the supply chain analysis are summarized in Table 8, which provides a detailed cost breakdown as well as greenhouse gas emissions. The greenhouse gas emissions analysis was completed by Argonne National Laboratory (ANL), using energy consumption and transportation distance data from the BLM. Table 9 compares modeled cost estimates for the herbaceous feedstock supply system for the 2019 Herbaceous SOT, 2020 Herbaceous SOT, 2020 $\mathrm{n}^{\text {th }}$-Supply SOT and the 2022 Herbaceous Projection.

Table 8. The 2020 Herbaceous $n^{\text {th }}$-Supply SOT modeled cost and GHG estimates for an herbaceous feedstock supply system supplying 725,000 dry tons annually in northwestern Kansas. Design details are in Appendix A and the nth-Supply scenario analysis and assumptions are reproduced in Appendix $B$.

\begin{tabular}{lcccc}
\hline \multirow{2}{*}{ Cost Element } & \multicolumn{4}{c}{ Cost $\mathbf{( \$ / d r y ~ t o n ) ~}$} \\
\cline { 2 - 5 } & $\begin{array}{c}\text { Three-Pass } \\
\text { Stover }\end{array}$ & $\begin{array}{c}\text { Two-Pass } \\
\text { Stover }\end{array}$ & $\begin{array}{c}\text { Least-Cost } \\
\text { Blend }^{\mathbf{b}}\end{array}$ & $\begin{array}{c}\text { GHG emissions } \\
\text { (kg CO }_{2} \mathbf{e} / \text { ton) }\end{array}$ \\
\hline Blend Ratio & $29.63 \%$ & $70.37 \%$ & $100.00 \%$ & \\
\hline Grower payment & $\$ 21.71$ & $\$ 20.16$ & $\$ 20.62$ & \\
\hline Harvest and collection & $\$ 13.84$ & $\$ 18.79$ & $\$ 17.33$ & 11.17 \\
\hline Storage and queuing & $\$ 6.66$ & $\$ 6.74$ & $\$ 6.72$ & 2.50 \\
\hline Transportation and handling & $\$ 11.66$ & $\$ 13.74$ & $\$ 13.12$ & 14.00 \\
\hline In-plant receiving and preprocessing & $\$ 19.60$ & $\$ 19.60$ & $\$ 19.60$ & 47.21 \\
\hline Dockage & $\$ 2.59$ & $\$ 0.89$ & $\$ 1.39$ & \\
\hline Total & $\mathbf{\$ 7 6 . 0 6}$ & $\$ 79.92$ & $\$ 78.78$ & $\mathbf{7 4 . 8 8}$ \\
\hline
\end{tabular}

a Pesticide and fertilizer emissions incurred during biomass production were attributed to the biomass growth stage of the life cycle and are not included.

b The blend costs are presented as the weighted average of the blend component costs.

c Grower payment taken as the cost assumed for procurement of grass clippings. 


\section{Idaho National Laboratory}

Table 9. Summary of modeled cost estimates for the herbaceous feedstock supply system for biochemical conversion pathway for the 2019 SOT, 2020 SOT, $2020 n^{\text {th }}$-Supply SOT and 2022 Projection.

\begin{tabular}{|c|c|c|c|c|}
\hline & $\begin{array}{l}2019 \\
\text { SOT }\end{array}$ & $\begin{array}{l}2020 \\
\text { SOT }\end{array}$ & $\begin{array}{c}2020 \\
\mathbf{n}^{\text {th }} \text {-Supply } \\
\text { SOT }\end{array}$ & $\begin{array}{c}2022 \\
\text { Projection }\end{array}$ \\
\hline Feedstock & Blend & Blend & Blend & Blend \\
\hline Net delivered cost (\$/dry ton) & $\$ 81.37$ & $\$ 80.10$ & $\$ 78.78$ & $\$ 79.07$ \\
\hline Grower payment (\$/dry ton) & $\$ 20.56$ & $\$ 20.62$ & $\$ 20.62$ & $\$ 22.37$ \\
\hline Feedstock logistics (\$/dry ton) & $\$ 60.81$ & $\$ 59.47$ & $\$ 58.16$ & $\$ 56.70$ \\
\hline Harvest \& collection (\$/dry ton) & $\$ 17.14$ & $\$ 17.33$ & $\$ 17.33$ & $\$ 12.79$ \\
\hline Storage \& queuing (\$/dry ton) & $\$ 6.49$ & $\$ 6.72$ & $\$ 6.72$ & $\$ 8.35$ \\
\hline Preprocessing (\$/dry ton) & $\$ 20.84$ & $\$ 19.43$ & $\$ 19.60$ & $\$ 21.44$ \\
\hline Transportation \& handling (\$/dry ton) & $\$ 14.76$ & $\$ 14.61$ & $\$ 13.12$ & $\$ 12.44$ \\
\hline Dockage (\$/dry ton) & $\$ 1.58$ & $\$ 1.39$ & $\$ 1.39$ & $\$ 1.68$ \\
\hline
\end{tabular}

In the 2020 Herbaceous $n^{\text {th }}$-Supply SOT, the technologies, biomass physical and chemical quality parameters, and process flows are identical to those used in the analysis presented Section 2 for the 2020 Herbaceous SOT presented in Section 2. As a result, the delivered quantities and compositions of the biomass sources, the preprocessed blendstocks produced and the least-cost blend are the same as in the 2020 Herbaceous SOT. Due to the higher biomass availability in the POLYSYS demand run, a lower transportation cost is estimated for the 2020 Herbaceous $n^{\text {th }}$-Supply SOT. There is a small increase of $\$ 0.17 /$ dry ton in the depot construction cost compared to the 2020 Herbaceous SOT because of differences in depot size. Overall, by incorporating the biomass availability and depot locations optimized or the demand-based supply from the POLYSYS demand runs, the delivered feedstock cost is decreased by $\$ 1.31$ /dry ton. Noting that this brings the delivered cost below the 2022 Herbaceous Projection which was based on projected 2022 supply curves from BT-16, it will be necessary to recast the 2022 Herbaceous Projection to the nth-supply scenario during FY21 to put them on the same supply basis for comparison. It will also be necessary in the future to recast the 2030 Herbaceous Projection of $\$ 71.26$ /dry ton $(2016 \$)$ to bring the SOTs and targets to the same supply basis.

The $\mathrm{n}^{\text {th }}$-supply scenario depot locations, biomass source counties and biorefinery location are listed in Tables 10 and 11 and are shown pictorially in Figure 6. The least cost supply chain network utilized two distributed depots (Nodes 7 and 8 in Figure 6) for a biorefinery located in Sheridan County, Kansas. Because of the higher biomass availability around Node 8, the depot at Node 8 is sized larger than the one at Node 7. In order not to exceed the capacity of depot in Node 7, three-pass corn stover purchased from Node 1 is delivered to the depot in Node 8 . The results also show that a biorefinery with a design capacity of 725,000 dry tons/year, would need to procure at least 811,180 dry tons of biomass annually to account for losses in the system. This procured biomass is 29,487 dry tons less than the 2019 Herbaceous SOT. 
Table 10. Node IDs and county names for the biomass source counties for the supply system depicted in Figure 5 for the 2020 Herbaceous $n^{\text {th }}$-Supply SOT. Decatur County, KS and Phillips County, KS are not identified in the table because they are depot locations but not farm-gate sources of biomass.

\begin{tabular}{cl}
\hline Node & \multicolumn{1}{c}{ County } \\
\hline- & Sheridan County, KS \\
\hline 1 & Frontier County, NE \\
\hline 2 & Gosper County, NE \\
\hline 3 & Phelps County, NE \\
\hline 4 & Kearney County, NE \\
\hline 5 & Harlan County, NE \\
\hline 6 & Franklin County, NE \\
\hline
\end{tabular}

Table 11. Locations and sizes of distributed depots for least cost delivery of 725,000 dry tons/year of blended feedstock to Sheridan County, KS for the 2020 Herbaceous $n^{\text {th }}$-Supply SOT. Source nodes are identified by county name in Table 9 and are shown geographically in Figure 6.

\begin{tabular}{|c|c|c|c|c|c|}
\hline Node & Identifier & County & $\begin{array}{c}\text { Capacity } \\
\text { (dry tons/yr) }\end{array}$ & Biomass Type & $\begin{array}{c}\text { Biomass } \\
\text { Source } \\
\text { Nodes } \\
\end{array}$ \\
\hline- & Biorefinery & Sheridan, KS & 725,000 & Blend & 7,8 \\
\hline 7 & Depot & Decatur, KS & 195,315 & $\begin{array}{l}\text { two-pass } \\
\text { corn stover }\end{array}$ & 1,2 \\
\hline \multirow{2}{*}{8} & \multirow{2}{*}{ Depot } & \multirow{2}{*}{ Phillips, KS } & \multirow{2}{*}{529,685} & $\begin{array}{l}\text { three-pass } \\
\text { corn stover }\end{array}$ & 1,5 \\
\hline & & & & $\begin{array}{l}\text { two-pass } \\
\text { corn stover }\end{array}$ & $3,4,6$ \\
\hline
\end{tabular}




\section{INL batro Notiond lobocion}

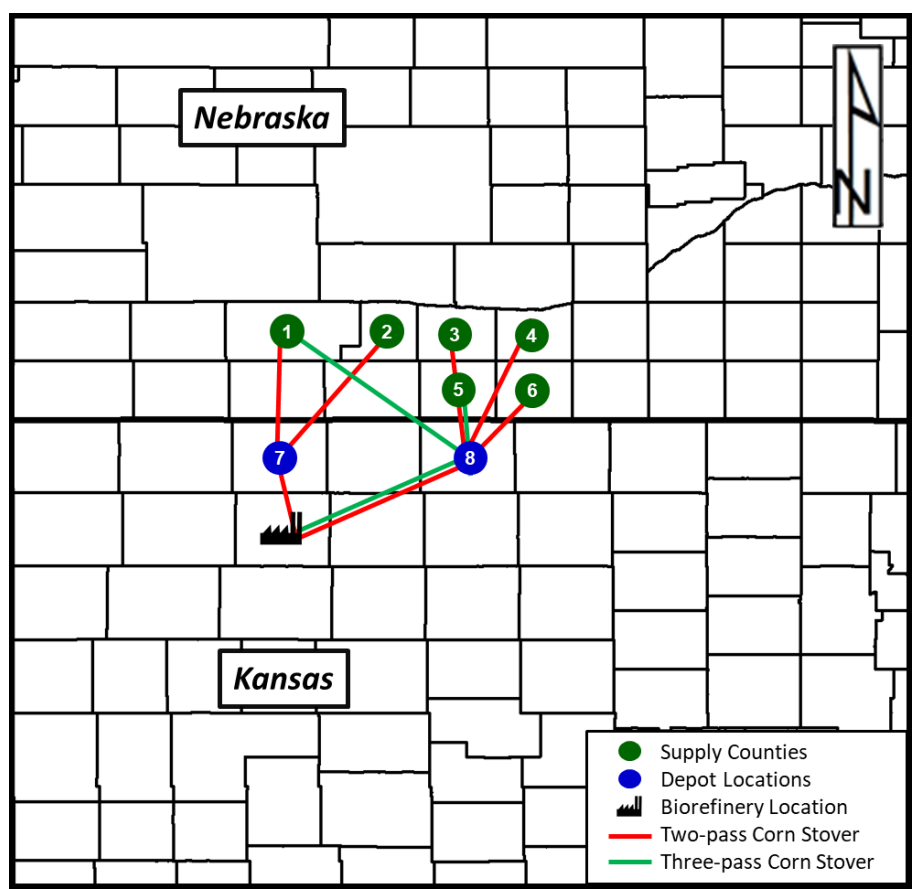

Figure 6. Supply chain network design for the 2020 Herbaceous $n^{\text {th }}$-Supply SOT. The supply chain has 2 distributed depots (Nodes $=7$ and 8) with the biorefinery located in Sheridan County, Kansas. Three-pass corn stover is sourced from Nodes 1 and 5. Two-pass corn stover is sourced from Nodes 1, 2, 3, 4 and 6. County names are shown with their node identifiers in Table 9 and Table 10.

\subsection{Sensitivity Analysis of Costs}

The total delivered cost was found to vary in the range from $\$ 75.80-\$ 84.04 /$ dry ton (2016\$). Because the technologies, critical processes, and key operational parameters for the 2020 Herbaceous $n^{\text {th }}$-Supply SOT design scenario are the same as for the 2020 Herbaceous SOT presented in Section 2, the key contributors to uncertainty and the uncertainly ranges are identical to those presented in Figure 4.

\section{SUMMARY}

The Feedstock Technologies platform within BETO focuses on (1) reducing the delivered cost of sustainably produced biomass; (2) preserving and improving the physical and chemical quality parameters of harvested biomass to meet the individual needs of biorefineries and other biomass users; and (3) expanding the quantity of feedstock materials accessible to the bioenergy industry. To support BETO and its bioenergy production goals, INL completes annual SOT reports for herbaceous and woody biomass feedstock logistics. This report provides the status of 


\section{Idaho National laboratory}

technology development of feedstock logistics for herbaceous biomass to biofuels utilizing experiment-based data and results and provides a relative comparison to technical targets and costs goals from design cases.

Although CFSS forms the backbone of the emerging biofuels industry, they have limitations that restrict widespread implementation on a national scale. To meet the demands of the future industry, the feedstock supply system must shift from the conventional system to what has been termed "advanced" supply systems. In advanced designs, a distributed network of aggregation and processing centers, termed "depots," are employed near the points of biomass production (i.e., the field or forest) to reduce feedstock variability and produce feedstocks of a uniform format, moving toward biomass commoditization. The 2020 Herbaceous SOT is part of a longer-term vision of achieving an implemented advanced feedstock supply system, which produces a stable, tradable commodity at the decentralized distributed depot.

The 2020 Herbaceous SOT incorporates an actively managed storage system for earlyharvested bales which are typically $>30 \%$ moisture. The storage system utilizes a combination of best management practices and "farm-scale technologies" such as enhanced in-storage drying to achieve storage stability objectives. A wrapped-bale mechanical ventilation concept for these very wet bales utilizes a combination of microbial self-heating and advective air flow (supplied by a commercial grain dryer blower) to reduce stack moisture from $30 \%$ to $<20 \%$ in 30 days. This technical improvement positively affects storage dry matter loss and feedstock preprocessing performance within the feedstock logistics system.

Previous SOT results have confounded biomass supply assumptions from BT-16 that predicted an increasing supply year on year. To get a clearer presentation of cost impacts of technology improvements, for the 2020 SOT we utilized the same supply curves from BT-16 that were used for the 2019 SOT. The 2020 Herbaceous SOT report documents the current modeled cost of an herbaceous feedstock supply system from harvest to the pretreatment reactor throat for hydrocarbon fuel production via biochemical conversion, based on equipment and processes now available or potentially available in the near term. The modeled cost also considers both the required quality and the availability of the biomass resources. The 2020 Herbaceous SOT predicts a modeled delivered feedstock cost of $\$ 80.10 /$ dry ton $(2016 \$)$; this is a $\$ 1.27$ /dry ton (2016\$) decrease from the 2019 Herbaceous SOT. Technology improvements that contributed to this modeled cost reduction include reduced cost in the feedstock preprocessing caused by reduced moisture from the newly designed field side storage. A greenhouse gas emissions (GHG) assessment was completed by Argonne National Laboratory using the 2020 Greenhouse Gases, Regulated Emissions, and Energy use in Transportation model (GREET), estimating a decrease of up to $6.68 \mathrm{~kg} \mathrm{CO}_{2} \mathrm{e} / \mathrm{ton}$ from the $2019 \mathrm{SOT}$ (84.16 $\mathrm{kg} \mathrm{CO}_{2} \mathrm{e} /$ ton in the $2019 \mathrm{SOT}$ to $77.48 \mathrm{~kg} \mathrm{CO}_{2} \mathrm{e} /$ ton in the 2020 Herbaceous Feedstock SOT). This net reduction is attributed to reduced energy consumption in the hammer mill, reduced high emission feedstock used in the blend (less three-pass corn stover), and incorporation of the updated GREET model.

Moving forward in future years, we will implement use of the $\mathrm{n}^{\text {th }}$-supply scenario developed in FY19 and FY20 as a constant supply in order to focus on improvements due to BETO-funded technology improvements. Hence, in this report we also present the 2020 Herbaceous SOT recast using the supply curves and optimal depot and biorefinery locations 


\section{Idaho National Laboratory}

determined for the $\mathrm{n}^{\text {th }}$-supply scenario (see Appendix B); this is presented in this report as the 2020 Herbaceous $\mathrm{n}^{\text {th }}$-Supply SOT. Overall, by incorporating the biomass availability and depot locations optimized or the demand-based supply from the POLYSYS demand runs, the delivered feedstock cost was decreased by $\$ 1.31$ dry ton. Noting that this brings the delivered cost below the 2022 Herbaceous Projection which was based on projected 2022 supply curves from BT-16, it will be necessary to recast the 2022 Herbaceous Projection to the $\mathrm{n}^{\text {th }}$-supply scenario during FY21 to put them on the same supply basis for comparison. It will also be necessary in the future to recast the 2030 Herbaceous Projection of \$71.26/dry ton (2016\$) to bring the SOTs and targets to the same supply basis.

\section{REFERENCES}

Anderson, E. K., Parrish, A. S., Voigt, T. B., Owens, V. N., Hong, C.-H. and Lee, D. (2013). "Nitrogen fertility and harvest management of switchgrass for sustainable bioenergy feedstock production in Illinois." Industrial Crops and Products 48: 19-27.

Aqa, S. and Bhattacharya, S. (1992). "Densification of preheated sawdust for energy conservation." Energy 17(6): 575-578.

Bhattacharya, S. (1993). "State-of-the-art of utilizing residues and other types of biomass as an energy source." RERIC International Energy Journal 15(1): 1-21.

Bhattacharya, S., Sett, S. and Shrestha, R. M. (1989). "State of the art for biomass densification." Energy Sources 11(3): 161-182.

Birrell, S. J., Karlen, D. L. and Wirt, A. (2014). "Development of sustainable corn stover harvest strategies for cellulosic ethanol production." BioEnergy Research 7(2): 509-516.

Bonner, I. J., Cafferty, K. G., Muth, D. J., Tomer, M. D., James, D. E., Porter, S. A. and Karlen, D. L. (2014). "Opportunities for Energy Crop Production Based on Subfield Scale Distribution of Profitability." Energies 7(10): 6509-6526.

Brue, J. D., Darr, M. J., Bergman, R. W. and Webster, K. (2015). "Understanding management practices for biomass harvest equipment for commercial scale operation." 2015 ASABE Annual International Meeting, American Society of Agricultural and Biological Engineers, DOI 10.13031/aim.20152189505.

Cafferty, K., Jacobson, J. and Kenney, K. (2013a). "Herbaceous/Biochem Feedstock 2013 State of Technology Report." Idaho National Laboratory, Idaho Falls, ID.

Cafferty, K. G., Muth, D. J., Jacobson, J. J. and Bryden, K. M. (2013b). "Model Based Biomass System Design of Feedstock Supply Systems for Bioenergy Production." ASME 2013 International Design Engineering Technical Conferences and Computers and Information in Engineering Conference, Portland, OR, USA, ASME.

Comer, K. (2017). "BALES Project Review 2017. Presentation at DOE Bioenergy Technologies Office (BETO) 2017 Project Peer Review Feedstock Supply \& Logistics Session". 


\section{Idaho National Laboratory}

Davis, R., Tao, L., Tan, E. C. D., Biddy, M. J., Beckham, G. T., Scarlata, C., Jacobson, J., Cafferty, K., Ross, J., Lukas, J., Knorr, D. and Schoen, P. (2013). "Process Design and Economics for the Conversion of Lignocellulosic Biomass to Hydrocarbons: Dilute-Acid and Enzymatic Deconstruction of Biomass to Sugars and Biological Conversion of Sugars to Hydrocarbons." National Renewable Energy Laboratory, Golden, CO, NREL/TP-5100-60223.

DOE (2016a). "Multi-Year Program Plan." U.S. Department of Energy, Bioenergy Technologies Office, Washington, DC, DOE/EE-1385, March 2016.

DOE (2016b). " 2016 Billion-Ton Report: Advancing Domestic Resources for a Thriving Bioeconomy, Volume 1: Economic Availability of Feedstocks." M. H. Langholtz, B. J. Stokes, and L. M. Eaton (Leads). Oak Ridge National Laboratory, Oak Ridge, TN, ORNL/TM-2016/160.

DOE. (2017). "Growing Bioeconomy Markets: Farm-to-Fuel in Southside Virginia." from https://www.youtube.com/watch?v=1yjx9wHmiTY

Graham, R., Langholtz, M., Eaton, L., Jacobson, J., Wright, C., Muth, M., Inman, D., Tan, E., Wu, M., Chiu, Y., Jones, S., Snowden-Swan, L. and Argo, A. (2013). "Investigation of Biochemical Biorefinery Sizing and Environmental Sustainability Impacts for Conventional Bale System and Advanced Uniform Biomass Logistics Designs." Biofuels, Bioproducts and BioPower, DOI: 10.1002/bbb.1391.

GREET. (2016). "Greenhouse Gas, Regulated Emissions and Energy Use in Transportation (GREET) model." Retrieved 09.05.2016, 2016, from https://greet.es.anl.gov/.

Hartley, D. S., Thompson, D. N., Griffel, L. M. (2020). “The effect of biomass properties and system configuration on the operating effectiveness of biomass to biofuel systems." ACS Sustainable Chemistry \& Engineering (2020), 8: 7267-7277. DOI: 10.1021/acssuschemeng.9b06551.

Hess, J. R., Kenney, K., Ovard, L., Searcy, E. and Wright, C. (2009a). "Uniform-format solid feedstock supply system: a commodity-scale design to produce an infrastructure-compatible bulk solid from lignocellulosic biomass." INL/EXT-08-14752, Idaho National Laboratory.

Hess, J. R., Kenney, K. L., Ovard, L. P., Searcy, E. M. and Wright, C. T. (2009b). "Commodityscale production of an infrastructure-compatible bulk solid from herbaceous lignocellulosic biomass." Uniform-format Bioenergy feedstock supply system design report series, Idaho National Laboratory, Idaho Falls, ID, INL/EXT-09-17527.

Hoskinson, R. L., Karlen, D. L., Birrell, S. J., Radtke, C. W. and Wilhelm, W. W. (2007). "Engineering, nutrient removal, and feedstock conversion evaluations of four corn stover harvest scenarios." Biomass and Bioenergy 31: 126-136.

Jacobson, J. J., Roni, M. S., Cafferty, K., Kenney, K., Searcy, E. and Hansen, J. K. (2014). "Biomass feedstock supply system design and analysis." Idaho National Laboratory, Idaho Falls, Idaho, INL/EXT-14-33227. 


\section{Idaho National Laboratory}

Lindsey, K., Johnson, A., Kim, P., Jackson, S. and Labbé, N. (2013). "Monitoring switchgrass composition to optimize harvesting periods for bioenergy and value-added products." Biomass and Bioenergy 56: 29-37.

Peters, M. S., C. D. Timmerhaus and West, R. E. (1968). Plant Design and Economics for Chemical Engineers. New York, NY, McGraw-Hill.

Roni, M., Hansen, J., Griffel, M., Hartley, D., Mamun, S. and Vazhnik, V. (2018). "Enabling Sustainable Landscape Design for Continual Improvement of Operating Bioenergy Supply Systems". Idaho Falls, Idaho, USA, Idaho National Laboratory INL/MIS-18-51176

Roni, M., Lin, Y., Thompson, D. N., Hartley, D.,Cai, H.. 2019 (a). Herbaceous Feedstock 2019 State of Technology Report. Idaho National Laboratory.

Roni, M.S., Thompson, D.N. and Hartley, D.S., 2019 (b). Distributed biomass supply chain cost optimization to evaluate multiple feedstocks for a biorefinery. Applied Energy, 254, p.113660.

Schmitt, E., Bura, R., Gustafson, R., Cooper, J. and Vajzovic, A. (2012). "Converting lignocellulosic solid waste into ethanol for the State of Washington: an investigation of treatment technologies and environmental impacts." Bioresource Technology 104: 400-409.

Searcy, E. and Hess, J. (2010). "Uniform-format feedstock supply system: A commodity-scale design to produce an infrastructure-compatible biocrude from lignocellulosic biomass." Idaho National Laboratory, Idaho Falls, Idaho, INL/EXT-10-20372.

Searcy, E., Lamers, P., Hansen, J., Jacobson, J., Hess, J.R. and Webb, E. (2015). "Advanced Feedstock Supply System Validation Workshop SUMMARY REPORT." Idaho National Laboratory, Idaho Falls, ID. INL/EXT-15-50315.

Shah, A., Darr, M. J., Webster, K. and Hoffman, C. (2011). "Outdoor storage characteristics of single-pass large square corn stover bales in Iowa." Energies 4(10): 1687-1695.

Shinners, K. J., Bennett, R. G. and Hoffman, D. S. (2012). "Single and two-pass corn grain and stover harvesting." Transactions of the ASABE 55(2): 341-350.

Smith, W. and Bonner, I. (2012). "Demonstrate through integrated model analysis using field and PDU-scale data from dry corn stover a total feedstock logistics cost of $\$ 35.00$ per dry ton (excluding grower payment, in 2007\$)." Idaho National Laboratory Idaho Falls, ID, Milestone Completion Report-1.2.1.1.

Smith, W. and Plummer, M., (2020). " Evaluate modeled operational performance of actively managed storage systems." Idaho National Laboratory Idaho Falls, ID, Milestone Completion Report-1.2.1.1.

Smith, W. and Bonner, I. (2014). "Evaluation of two multi-pass stover harvest systems and their impacts on the interactions between yield and ash on the delivered feedstock price." Idaho National Laboratory, Idaho Falls, ID, Milestone Completion Report, Biomass

Engineering-1.2.1.1 Harvest, Collection, \& Storage; Award Number 15076, March 31, 2014. 
Sokhansanj, S., Webb, E. and Turhollow Jr, A. F. (2014). "Simulation of the DOE High-Tonnage Biomass Logistics Demonstration Projects: Auburn University." Oak Ridge National Laboratory, Oak Ridge, TN, ORNL/TM-2014/505.

STINGER (2015). "Baled biomass from field to factory.", Stinger.

Tumuluru, J. S. (2014). "Effect of process variables on the density and durability of the pellets made from high moisture corn stover." Biosystems Engineering 119: 44-57.

Tumuluru, J. S., Wright, C. T., Kenny, K. L. and Hess, J. R. (2010). "A review on biomass densification technologies for energy application." Idaho National Laboratory, Idaho Falls, ID, INL/EXT-18420.

Webb, E., Sokhansanj, S. and Turhollow Jr, A. F. (2013a). "Simulation of the DOE HighTonnage Biomass Logistics Demonstration Projects: AGCO Corporation." Oak Ridge National Laboratory, Oak Ridge, TN, ORNL/TM-2013/323.

Webb, E., Sokhansanj, S. and Turhollow Jr, A. F. (2013b). "Simulation of the DOE HighTonnage Biomass Logistics Demonstration Projects: FDC Enterprises." Oak Ridge National Laboratory, Oak Ridge, TN, ORNL/TM-2013/338.

Webb, E., Sokhansanj, S. and Turhollow Jr, A. F. (2013c). "Simulation of the DOE HighTonnage Biomass Logistics Demonstration Projects: State University of New York College of Environmental Science and Forestry." Oak Ridge National Laboratory, Oak Ridge, TN, ORNL/TM-2013/376.

Webb, E. and Sokhansanj, S. (2014). "Sensitivity Analysis of Biomass High-Tonnage Logistics Demonstration Projects." Oak Ridge National Laboratory, Oak Ridge, TN, ORNL/TM-2013/568.

Wendt, L., Bonner, I., Smith, W., Plummer, M. and Earl, J. (2013). "Quantify structural sugar loss in storage relative to initial moisture content and oxygen availability." Idaho National Laboratory Idaho Falls, ID, Milestone Completion Report-1.2.1.1000. 


\section{Idaho National Laboratory}

\section{APPENDIX A - 2020 Herbaceous State of Technology Feedstocks Logistics Design and Assumptions}

The 2020 Herbaceous SOT provides an annual herbaceous feedstock supply to a biorefinery located in Sheridan County, Kansas (northwestern Kansas) consisting of 725,000 dry tons of an herbaceous biomass blend comprised of $29.63 \%$ three-pass stover and $70.37 \%$ two-pass stover. The 2020 Herbaceous SOT incorporates two depots (identified as Nodes 23 and 25 in Figure 4 and Table 5 of the main document, and Figure A-1 in this appendix).

The 2020 Herbaceous SOT couples feedstock logistics with resource availability, reflected as grower payment, to estimate the delivered feedstock cost required to supply the biorefinery. The design is located in an area of relatively low biomass productivity, consistent with the 2013-2019 Herbaceous SOTs, to conservatively include the barriers and cost implications for meeting national targets for a national scale biorefinery industry. When biomass must be sourced in locations where there is insufficient biomass supply at the specified quality but there is also a diversity of biomass types available, blending options become available to assist in meeting conversion quality specifications. Grower payments were calculated from farm gate prices by subtracting modeled harvest and collection costs and scaling to the appropriate year.

The three-pass corn stover harvest and collection method modeled in this analysis is consistent with those used in conventional systems referred to as "multi-pass harvesting systems." The two-pass corn stover harvesting and collection method modeled is an advanced harvest method that has been utilized by Poet-DSM to harvest corn stover for its Emmetsburg, IA facility. In this method, the first pass is grain harvest using a combine with header raised to just below the ear on the corn stalks and the spreader turned off, and the second pass is a baler (Birrell et al. 2014; Shinners et al. 2012). This eliminates the windrowing step, which is a significant source of soil entrainment in the baled corn stover. The raised header (higher cut height) leads to a lower harvest yield and is generally a conservative approach to ensure soil sustainability. The three-pass stover and two-pass stover are harvested, collected, and then stored field-side (tarped) until being transported by truck to the main depot in bales.

The modeled supply chain for the 2020 Herbaceous SOT utilizes general purpose depots in the sense that they employ identical preprocessing equipment in each, and can receive any of the sources of stover or switchgrass (see Table 6 and Figure A-1). The baled biomass delivered from road-side storage at the farm gates of the supplying counties is size reduced using hammer milling/fractional milling, densified using high moisture pelleting, and then cooled and placed into temporary depot storage until shipping to the biorefinery when needed. Pellets shipped from these depots to the biorefinery are placed into silos (separated by biomass type) when received and blended to the correct ratio immediately prior to feeding to the reactor throat. The silos serve as the metering bin for the conversion process, as the pellets are blended as they are conveyed to the feeding system for the pretreatment reactor. 


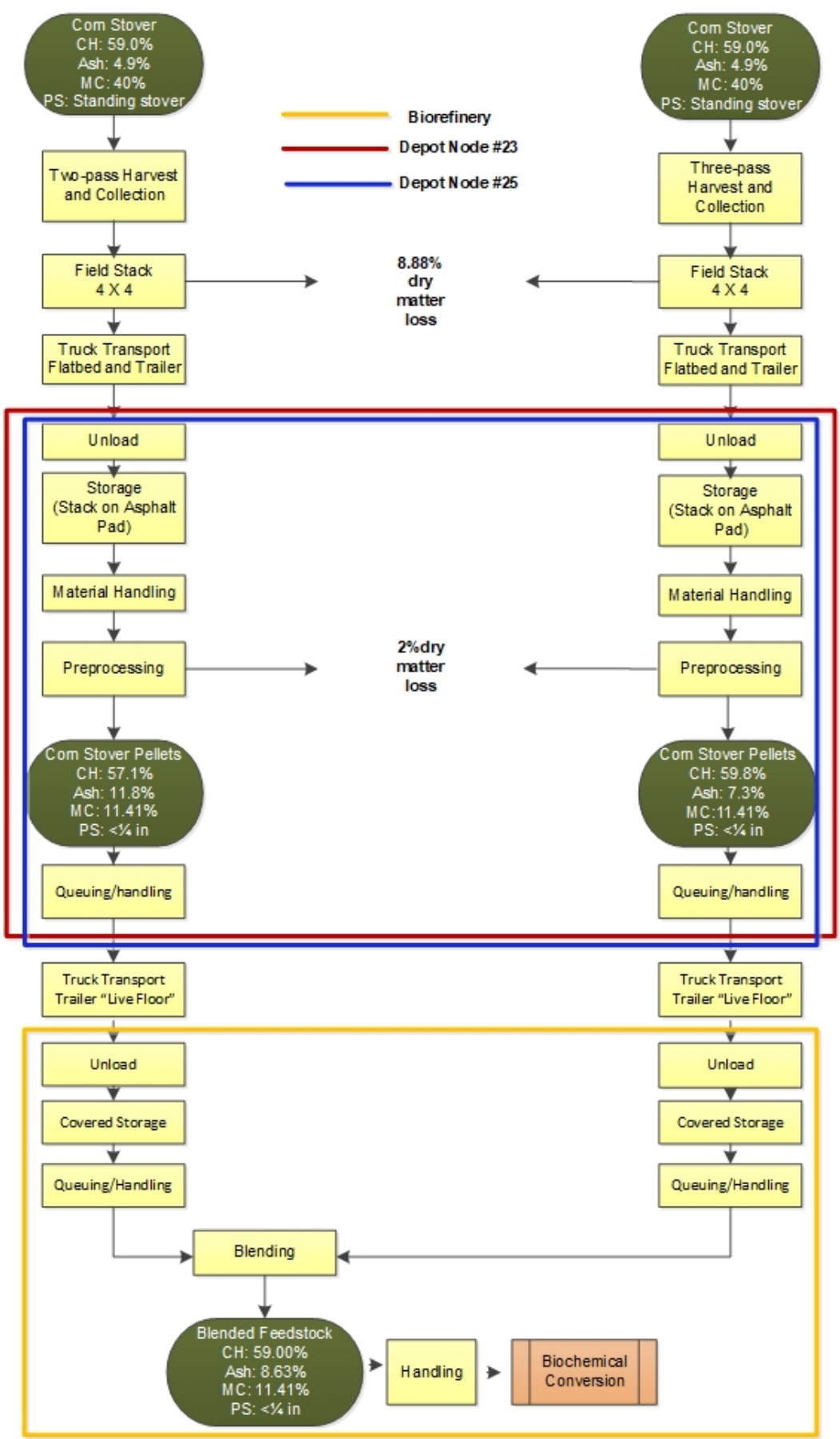

Figure A-1. The modeled 2020 Herbaceous SOT feedstock supply system. $C H=$ Carbohydrate content, $M C=$ moisture content, $P S=$ Particle size. Depots are identified as nodes 23 and 25. Optimal locations and sizes of these nodes are listed in Figure 3 and Table 5 and 6 of the main body of this report. 


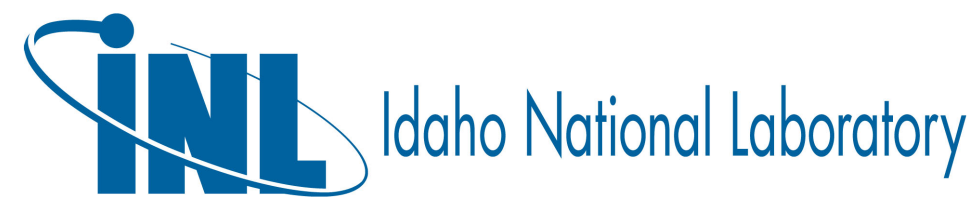

\section{Resource Availability}

The geographic area chosen for the 2020 Herbaceous SOT is northwestern Kansas, with the biorefinery located in Sheridan County. It was assumed that all corn stover and switchgrass biomass as identified in the BT16 report located in Kansas, Nebraska and Colorado would be potentially available to meet the demand of 725,000 dry tons delivered to the pretreatment reactor throat at the biorefinery. The available corn stover was estimated from the 2019 countylevel data in the BT16 report (DOE 2016b) and modified through implementation of the ILM strategy (Roni et al. 2019a). Corn stover availability in BT16 is representative of conventional three-pass harvesting. We assumed that two-pass harvesting would be limited to high-yielding counties (defined as stover yields $\geq 2.0$ dry tons/acre), however, three-pass harvesting could also be utilized in these counties. We further assumed that only three-pass harvesting would be used in low-yielding counties (stover yields $<2.0$ tons/acre). This was done to maximize yields of corn stover from the low-yielding counties, which are significantly greater in number than highyielding counties.

Because two-pass harvesting cuts higher on the stalk, less stover is collected by the baler. In a multi-year study, Birrell et al. (2014) showed that two-pass harvest of material other than grain (MOG) reached about 35\% of the collection efficiency of conventional three-pass harvest. In another study (Smith et al. 2014), it was observed that the specific two-pass harvest method assumed in this SOT achieved slightly less than half the yield observed for the flail shred threepass harvest method assumed for this study (Table A-1). Three-pass harvesting with a flail shredder and square bales achieved 1.9-2.0 dry tons/acre, while the two-pass system achieved 0.9-1.0 dry tons per acre. The average ratio of two-pass yield/three-pass yield is then 0.487 . Hence, for the high-yielding counties, we adjusted the BT16 three-pass availabilities for corn stover down by a factor of 0.487 to give the two-pass availability numbers for the analysis. 
Table A-1. Baled corn stover yield and mean ash contents in three-pass harvesting (Rake, Flail), and two-pass harvesting (MOG) (Smith et al. 2014). We assumed square bales for transportation; relevant treatments in the table are in bolded text. The flail treatment (ISU '12 3.2) was not used because its low ash content is inconsistent with the other flail treatments.

\begin{tabular}{|c|c|c|c|c|}
\hline Windrow & Bale Type & ID & $\begin{array}{c}\text { Yield } \\
\text { (DMT/acre) }\end{array}$ & $\begin{array}{c}\text { Ash } \\
\text { (wt\% db) }\end{array}$ \\
\hline $\mathrm{MOG}^{\mathrm{a}}$ & Round & MOG-1 & 0.5 & 4.9 \\
\hline MOG & Round & MOG-2 & 0.6 & 3.8 \\
\hline MOG & Round & MOG-3 & 0.7 & 7.6 \\
\hline MOG & Round & MOG-4 & 0.7 & 6.8 \\
\hline MOG & Round & MOG-5 & 0.7 & 5.6 \\
\hline MOG & Round & MOG-6 & 0.8 & 6.3 \\
\hline MOG & Square & MOG-7 & 0.9 & 5.8 \\
\hline MOG & Square & MOG-8 & 1.0 & 5.3 \\
\hline Rake & Square & RAKE-1 $^{\mathrm{b}}$ & $0.9^{\mathrm{b}}$ & 8.1 \\
\hline Rake & Square & RAKE- $^{\text {b }}$ & $1.4^{\mathrm{b}}$ & 7.6 \\
\hline G-hoff & Square & G-HOF & 1.9 & 8.0 \\
\hline 1-P & Square & $1-\mathrm{PASS}^{\mathrm{c}}$ & 1.9 & 5.7 \\
\hline Flail & Square & FLAIL $^{c}$ & 2.0 & 13.9 \\
\hline Rake & Square & ISU '12 3.1 & 1.4 & 14.6 \\
\hline Flail & Square & ISU '12 3.2 & 1.4 & 7.6 \\
\hline Rake & Square & ISU '12 3.3 & 1.9 & 15.6 \\
\hline Flail & Square & ISU '12 3.4 & 1.9 & 12.1 \\
\hline
\end{tabular}

a The combine drops the material other than grain (MOG) into a loose windrow, which is followed by a separate baler. Drawbacks to this method are reduced collection efficiency and field "striping" as a result of uneven residue removal.

b Assumed average bale weight from previous co-located studies

c Provided by Matt Darr, Iowa State University 


\section{Process Design and Cost Estimation Details}

In this section, the costs of different supply chain operations are described along with key assumptions and input parameters.

\section{A.1 Interest Rate and Energy Cost Assumptions}

The 2020 Herbaceous SOT uses the same interest rate and energy cost assumptions used for the 2019 Herbaceous SOT as shown in Table A-2.

Table A-2. Energy prices and interest rates used to model herbaceous feedstock logistics costs for the 2020 Herbaceous SOT.

\begin{tabular}{lcc}
\multicolumn{1}{c}{ Component } & 2019 Assumptions & 2020 Assumptions \\
\hline Interest Rate & $8 \% \mathrm{a}^{\mathrm{a}}$ & $8 \% \mathrm{a}^{\mathrm{a}}$ \\
\hline Electricity Price & $\$ 0.0672 / \mathrm{kWh}^{\mathrm{b}}$ & $\$ 0.0672 / \mathrm{kWh}^{\mathrm{b}}$ \\
\hline Natural Gas Price & $\$ 3.36 / \mathrm{MMBtu}^{\mathrm{b}}$ & $\$ 3.36 / \mathrm{MMBtu}^{\mathrm{b}}$ \\
\hline Off-Road Diesel Price & $\$ 2.011 / \mathrm{gal}^{\mathrm{b}}$ & $\$ 2.011 / \mathrm{gal}^{\mathrm{b}}$ \\
\hline \multicolumn{2}{c}{ a See Jones et al. (2013) } \\
b See EIA (2018). Updated from the 2018 Herbaceous SOT using the Producer Price Index
\end{tabular}

\section{A.2 Harvest and Collection}

Although switchgrass was included in the available biomass sources, the optimized 2020 Herbaceous SOT design utilizes only corn stover biomass. Corn stover harvest is assumed to be available via two different harvesting methods, three-pass (conventional) harvesting and twopass harvesting (advanced). Conventional three-pass harvesting has the advantage of high yield, but the disadvantage of low quality with respect to carbohydrates (lower) and ash (higher). Twopass harvesting allows better quality but decreases the harvesting yield. Conventional three-pass systems involve cutting the feedstock, collecting the material into a windrow, and then baling the windrowed material (Figure A-2). The two-pass collection method eliminates the windrowing step and thereby reduces the potential for soil contamination (Shinners et al. 2012, Birrell et al. 2014). In this method, the combine drops the material other than grain (MOG) into a loose windrow, which is followed by a separate baler. The two-pass method assumed here has been utilized by POET-DSM's Advanced Biofuels' Project Liberty. Drawbacks to this method are reduced collection efficiency (due to a higher cut height) and field "striping" (Birrell et al. 2014) as a result of uneven residue removal. Two-pass collection does not increase the required throughput to the combine or hinder its operation but requires some minor operational modifications. Combine operation is altered by disengaging the straw choppers at the rear of the combine to allow the MOG to drop behind the combine into a loose windrow. The combine is modified by adding "stalk-stompers" or by mounting rollers under the header to bend the lower stalk over in the rows on which the MOG will be dropped. These devices are commonly (but not universally) used under the wheel-track rows to reduce the risk of tire punctures. They are optional equipment but are relatively inexpensive. 


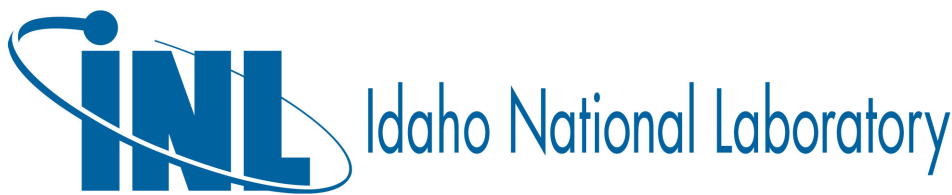

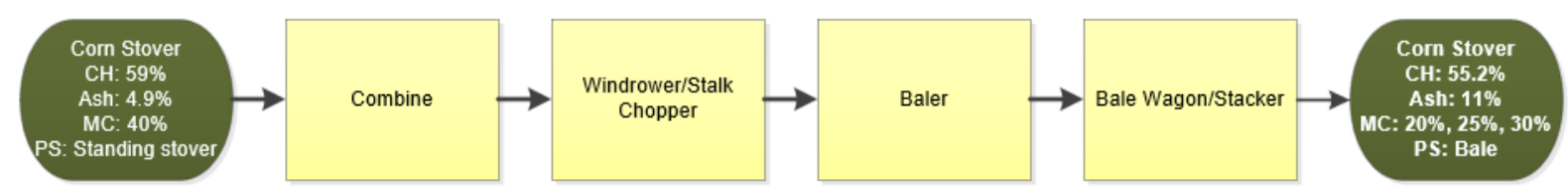

Corn stover : Three-pass harvesting \& collection

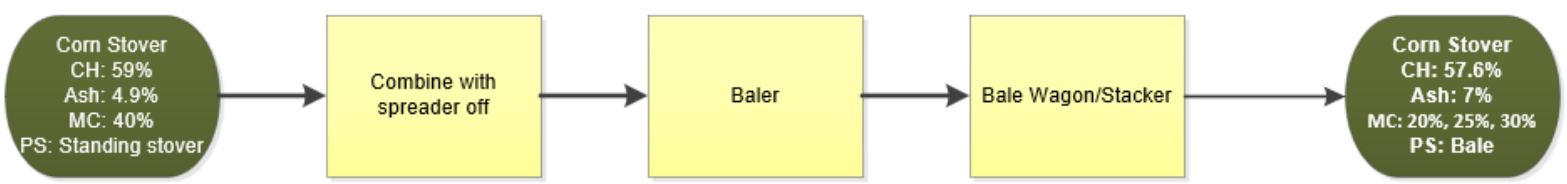

Corn stover : Two-pass harvesting \& collection

Figure A-2. The 2020 Herbaceous SOT harvest and collection operations for corn stover. It is assumed that prior to baling there is some amount of field, $50 \%$ of the total biomass will reach $25 \%$ moisture, $25 \%$ of the biomass will reach $20 \%$ moisture, and the remaining $25 \%$ of the biomass will reach $30 \%$ moisture. $C H=$ Carbohydrate content, $M C=$ moisture content, and $P S=$ Particle size.

Because of the higher cutting height in two-pass harvest, the stover yields are limited to the upper stalk, husk, cob, and some leaves, which (stated above) amount to about, or less than, 1 ton/acre. However, it is has been shown that two-pass MOG is lower in moisture and ash content (Hoskinson et al. 2007). Most of the ash variability is introduced from soil during baling. Corn stover yield could be potentially increased in the two-pass harvest and collection method by cutting stover lower in the stalk. This could be accomplished by using a stalk-chopping head, reducing the cutting height. However, with lower stalk comes more moisture and ash and the stalk chopping head requires more power and increases cost.

It was assumed that two-pass harvesting will be limited to high-yielding areas as a result of this stover yield limitation. Our reasoning is as follows: Pordesimo et al. (2005) demonstrated that at grain maturity, the above ground stover mass fraction is approximately equal to the grain mass, in that case 6.7 dry tons/acre and 207 bushels/acre for the stover and the grain, respectively. In a multi-year study (Birrell et al. 2014), two-pass baling resulted in 35\% stover yield with 186 bushels/acre grain yield. To recover 0.7 dry tons/acre (the experimentallyvalidated average two-pass yield used for estimating harvesting costs for two-pass harvest; see Table A-4) or more, it would be necessary to have grain yields of 372 bushels/acre, which is unlikely on low-yielding fields. This represents an average yield in the Corn Belt, meaning that half of the available fields will have yields below this value, thus, corn stover yields less than 0.7 dry tons/acre. Part of the quality benefit from two-pass harvest arises from lower levels of inorganics higher up the stalk. Hoskinson et al. (2007) showed elevated inorganic nutrient and total ash contents in the lower stalk materials relative to the upper stalk. Additionally, an analysis by Birrell et al. (2014) showed that a greater quantity of ash forming minerals ( $\mathrm{Al}, \mathrm{B}, \mathrm{Cu}, \mathrm{Fe}$, $\mathrm{Mn}$ ) were present in multi-pass bales relative to two-pass MOG bales collected from the same experimental plots. Hence, while upper stalk collection via two-pass baling yields less stover, the 


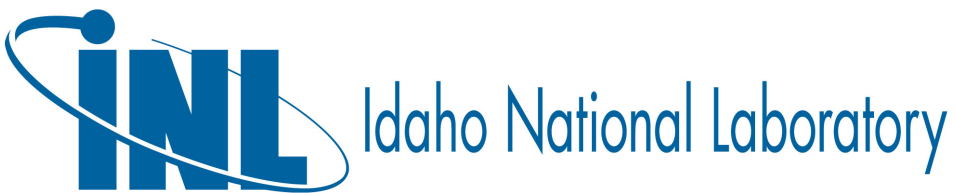

total ash content of the stover is lower, and there is a sustainability benefit since inorganic nutrient removal from the field is lower as well.

Table A-3 summarizes the harvest and collection design assumptions for the 2020 Herbaceous SOT. The assumed yield, capacity and efficiency of harvest and collections equipment, moisture content, and ash content were estimated based on published data (Anderson et al. 2013, Lindsey et al. 2013, Bonner et al. 2014, DOE 2016b, Owens et al. 2016), data from field trials (Smith et al. 2012, Smith et al. 2014, Brue et al. 2015), data taken from the INL Bioenergy Feedstock Library (INL 2016), and from personal communications ${ }^{1,2}$.

Table A-3. Harvest and collection design assumptions in the 2020 Herbaceous SOT for threepass corn stover and two-pass corn stover.

\begin{tabular}{|c|c|c|}
\hline \multirow[b]{2}{*}{ Component } & \multicolumn{2}{|c|}{ Corn stover } \\
\hline & $\begin{array}{c}\text { Three-Pass } \\
\text { Harvest }\end{array}$ & $\begin{array}{l}\text { Two-Pass } \\
\text { Harvest }\end{array}$ \\
\hline \multicolumn{3}{|l|}{ Harvest time } \\
\hline Operational hours & $\begin{array}{l}6 \text { weeks/year, } \\
6 \text { days/week, } \\
14 \text { hour/days }\end{array}$ & $\begin{array}{l}6 \text { weeks/year, } \\
6 \text { days/week, } \\
14 \text { hour/days }\end{array}$ \\
\hline \multicolumn{3}{|l|}{ Combine } \\
\hline Capacity & 41 tons/hour & 41 tons/hour \\
\hline Field efficiency & $70 \%$ & $70 \%$ \\
\hline Collection efficiency & $43 \%$ & $43 \%$ \\
\hline \multicolumn{3}{|c|}{ Stalk chopping windrower } \\
\hline Capacity & 11.5 acres/hour & $\mathrm{N} / \mathrm{A}^{\mathrm{a}}$ \\
\hline Efficiency & $80 \%$ & $\mathrm{~N} / \mathrm{A}$ \\
\hline \multicolumn{3}{|l|}{ Bale wagon/stacker } \\
\hline Capacity & 12 bales/load & 12 bales/load \\
\hline \multicolumn{3}{|l|}{ Baler } \\
\hline Capacity & 50 bales/hour & 25 bales/hour \\
\hline \multicolumn{3}{|l|}{ Harvest yield } \\
\hline Harvest yield & 1.2 tons/acre & 0.7 tons/acre \\
\hline
\end{tabular}

\section{A.3 Storage}

The 2020 Herbaceous SOT incorporates an actively managed storage system comprised of a combination of best management practices and "farm-scale technologies" such as enhanced

\footnotetext{
${ }^{1}$ Personal communication from Magen E. Shedden, a researcher at Oak Ridge National Laboratory (ORNL)

${ }^{2}$ Personal communication from William Smith, INL researcher
} 


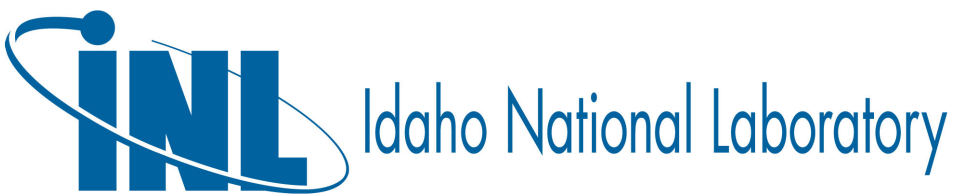

in-storage drying to achieve storage stability objectives. Storage research (WBS 1.2.1.1) evaluated modeled operational performance of actively managed storage systems. This actively storage managed storage consists of a microbial self-heating and advective flow system, supplied by a commercial grain dryer blower. Experimental results from the bale dryer (Fig. 2 in the main document) show that a single bale can be dried from $30 \%$ moisture to $<20 \%$ in two to four days, which implies that a stack that is 12 bales in length could be dried in 30 days. Drying experiments (Smith and Plummer, 2020) performed in INL's storage simulators showed that stover can be dried from $30 \%$ to $20 \%$ moisture at a range of flow rates with and incur dry matter losses of $5 \%$ or less. The primary factors that drive biological dry matter loss are moisture content of the biomass entering storage, the temperature and relative humidity as a function of time, oxygen availability, $\mathrm{pH}$, and the presence of inhibitory compounds in the biomass extractives component.

As the actively managed storage system only applies to the early harvested high moisture biomass, the 2020 Herbaceous SOT assumes that the moisture content of biomass prior to storage is distributed as follows: $25 \%$ of the biomass has $30 \%$ initial moisture (early harvested bales), $50 \%$ of the biomass has $25 \%$ initial moisture (bales harvested during the middle $50 \%$ of the harvest window), and the remaining $25 \%$ of the biomass has $20 \%$ initial moisture (late harvested bales). In the 2020 Herbaceous SOT, the dry matter losses are partitioned to individual corn stover components using the average observed losses of individual corn stover components during 3-month storage tests (Wendt et al. 2013) in the INL storage simulators at initial moisture contents ranging from 20-52\%. Tables A-4 and A-5 summarize dry matter loss and storage design assumptions applied in the 2020 Herbaceous SOT.

Table A-4. Average distribution of dry matter losses among corn stover components by initial moisture content.

\begin{tabular}{|c|c|c|}
\hline \multicolumn{2}{|c|}{ Biomass moisture content distribution } & \multirow{2}{*}{$\begin{array}{l}\text { DML after field } \\
\text { storage }\end{array}$} \\
\hline $\begin{array}{l}\% \text { of the total } \\
\text { biomass weight }\end{array}$ & $\begin{array}{l}\text { Initial Moisture } \\
\text { content }\end{array}$ & \\
\hline $25.00 \%$ & $20.00 \%$ & $7.70 \%$ \\
\hline $50.00 \%$ & $25.00 \%$ & $11.40 \%$ \\
\hline $25.00 \%$ & $30.00 \%$ & $5.00 \%{ }^{\mathrm{a}}$ \\
\hline
\end{tabular}

${ }^{\text {a }}$ Smith and Plummer, 2020

Table A-5. Field storage design assumptions for the 2020 Herbaceous SOT.

\begin{tabular}{l|l|l|l} 
Component & Storage TEA & Storage TEA & Storage TEA
\end{tabular}

\begin{tabular}{lll} 
parameters 1 & parameters 2 & parameters 3 \\
\hline
\end{tabular}




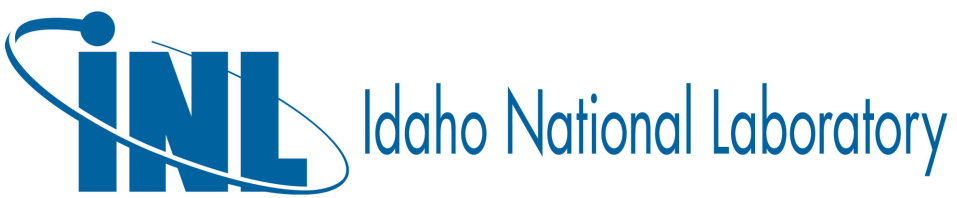

\begin{tabular}{lccc}
\hline Storage moisture content & $30 \%$ & $25 \%$ & $20 \%$ \\
\hline Storage dry matter loss & $5.0 \%$ & $11.4 \%$ & $7.7 \%$ \\
\hline Storage moisture loss & $10 \%$ & $5 \%$ & $0 \%$ \\
\hline Stack configuration & $3 \times 12$ wrapped stack & $4 \times 4$ tarped & $4 \times 4$ tarped \\
\hline Dryer Cost Basis $^{a}$ & $\$ 3.11 /$ dry ton $^{b}$ & - & - \\
\hline
\end{tabular}

(Dryer model: GSI 5-hp model GGI-80711)

${ }^{a}$ Dryer is used during daylight only.

${ }^{\mathrm{b}}$ Smith and Plummer (2020).

\section{A.4 Preprocessing}

The preprocessing technology in the 2020 Herbaceous SOT is identical to that utilized in the 2019 Herbaceous SOT. However, the preprocessing operating conditions and performance were updated based on the biomass properties exiting the new storage design. For example, since the biomass coming from storage will have lower moisture than the 2019 Herbaceous SOT, the hammer mill will consume less energy and will have higher throughput. Hence, the hammer mill performance has been updated in the 2020 Herbaceous SOT.

The 2020 Herbaceous SOT design utilizes high moisture pelleting in corn stover preprocessing. In high moisture pelleting, the biomass is preheated to approximately $110^{\circ} \mathrm{C}$ for short durations (typically $5 \mathrm{~min}$ ) prior to pelleting. Depending on the temperature used, preconditioning biomass by preheating it can affect both its chemical composition and its behavior during mechanical densification processes such as pelleting. When these changes impact mechanical properties, thereby changing the way the feedstock responds during densification, the overall quality of the pellets can be improved (Bhattacharya et al. 1989, Tumuluru et al. 2010). Preheating can also increase the throughput of the pellet mill and reduce the energy requirement per kilogram of biomass pellets produced. When the preheat temperature is high enough to impact chemical composition, preheating can also enable production of higherquality densified products for multiple end-use applications (Aqa et al. 1992, Bhattacharya 1993). Preheating in the presence of moisture can also promote softening of the natural binders in the biomass, including starch, lignin, and protein (Tumuluru 2014). Laboratory experiments performed under INL WBS 1.2.1.2 using flat-die and round-die pellet mills has shown that high durability pellets can be produced at an intermediate moisture content of 33-34\% (wet basis), preheating temperatures $>70^{\circ} \mathrm{C}$, and die speeds $>50 \mathrm{~Hz}$ (Tumuluru 2014).

As in the 2019 Herbaceous SOT, the 2020 Herbaceous SOT eliminates the drying step during preprocessing of corn stover. Pilot-scale testing of high moisture pelleting and cooling performed under INL WBS 1.2.1.2 indicated that the conservative moisture loss assumptions used in 2016 during grinding and pelleting could be increased, which eliminated the need for drying the pelleted biomass. Reduced energy consumption for high moisture pelleting was also observed in the pilot-scale ring die pellet mill tests, as compared to the lab-scale flat die pellet mill values utilized in the 2016 Herbaceous SOT. 


\section{TI. Idaho National laboratory}

The 2020 Herbaceous SOT utilizes the same percentage of material bypassed during fractional milling as 2019. As shown in Figure A-3, fractional milling inserts a screening operation (disk screen) between the first stage and second-stage size reduction operations (the bale processor and hammer mill, respectively) to remove the material that already meets the size

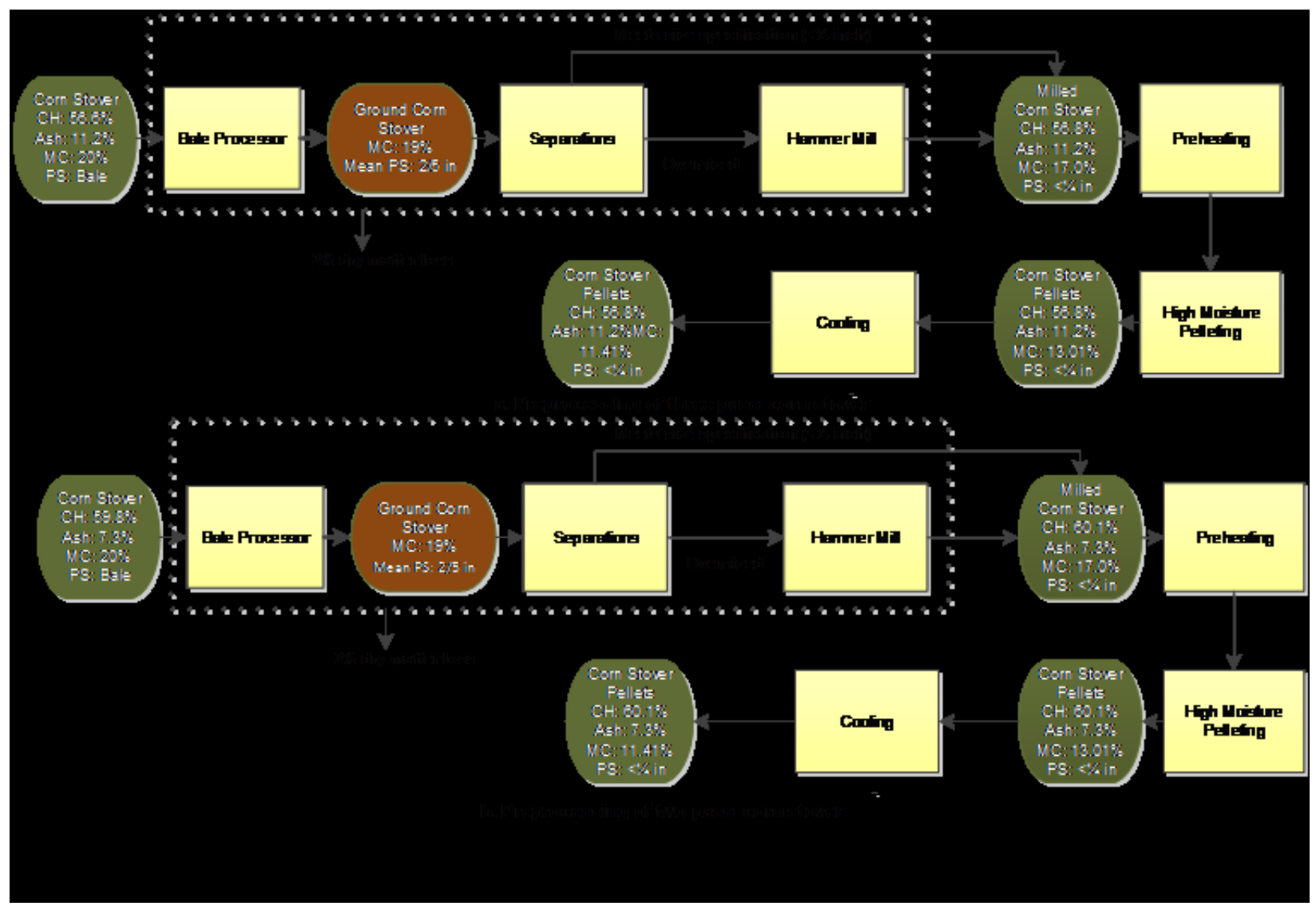

Figure A-3. 2020 Herbaceous SOT preprocessing configurations for corn stover. $\mathrm{CH}=$ Carbohydrate content, $M C=$ moisture content, $P S=$ particle size

specification before the material enters second-stage comminution. This reduces the amount of material that flows through the second-stage comminution, thereby reducing its size (cost) and energy consumption. In addition, fewer fines are produced because the material already meeting the particle size specification is not further size reduced. Hence, a tighter particle size distribution is achieved. Particle size distribution analysis shows that $30 \%$ of the corn stover material meets particle size requirements after the first-stage grinder and can bypass the secondstage size reduction, thereby leading to significant savings. Experiments performed in the Biomass Feedstock User Facility (BFNUF) at INL (WBS 1.2.3.3) have shown that 1-2\% of feedstock dry matter that arrives at the biorefinery gate is lost as dust during grinding, of which as much as $25 \%$ is ash. ${ }^{3}$ The organic fraction is generally comprised of fines generated from the

\footnotetext{
${ }^{3}$ Personal communication regarding dust collection during preprocessing from Neal Yancey, INL researcher
} 
leaves, which are thin and brittle and shatter from the hammer impacts during grinding.

Corn stover preprocessing for the 2020 Herbaceous SOT design is shown above in Figure A-3(a) for three-pass corn stover preprocessing, and Figure A-3(b) for two-pass harvesting. Although the preprocessing operations are identical for both corn stover sources, they have been shown separately because their initial and intermediate moisture contents and compositions are different (these are shown at various stages within the figures). Input parameters (such as throughput and energy consumption) have been updated in Table A-6 for corn stover, based on pilot-scale results (WBS 1.2.1.2).

Table A-6. Summary of 2020 Herbaceous SOT preprocessing assumptions. The benefit of fractional milling is included by adjusting the throughput and energy consumption of 2nd stage size reduction.

\begin{tabular}{lc}
\multicolumn{1}{c}{ Component } & Three-Pass \& Two-Pass Corn Stover \\
\hline Location of operation & Depot Nodes 23 and 25 \\
\hline Stage 1 size reduction & Bale processor \\
Grinder type & NA \\
\hline Screen Size (inch) & 8 \\
\hline Energy (kWh/dry ton) & 10 \\
\hline Throughput (dry ton/hour/machine) & $20.0 \%$ \\
\hline Operating conditions (moisture $\%)$ & Disc Screen \\
\hline Separations & Minimal electricity \\
\hline Screen type & 10 \\
\hline Energy (kWh/dry ton) & $19.0 \%$ \\
\hline Throughput (dry ton/hour/machine) & $30 \%$ \\
\hline Operating conditions (moisture $\%)$ & \\
\hline Bypass & Hammer mill \\
\hline Stage 2 Grinder & 0.25 \\
\hline Comminution method & $50\left(35^{\mathrm{a}}\right)$ \\
\hline Screen Size ( inch) & $2.04(2.92)$ \\
\hline Energy (kWh/dry ton) & $19.0 \%$ \\
\hline Throughput (dry ton/hour/machine) & \\
\hline Operating conditions (moisture $\%)$ & \\
\hline
\end{tabular}

Table A-6. (continued)

\begin{tabular}{lc}
\multicolumn{1}{c}{ Component } & Three-Pass \& Two-Pass Corn Stover \\
\hline Densifier & Pellet mill \\
\hline Densifier type & 33.79 \\
\hline Energy (kWh/dry ton) & 3.625 \\
\hline Throughput (dry ton/hour/machine) & \\
\hline
\end{tabular}




\section{SII Idoho National laboritory}

\begin{tabular}{lc}
\hline Operating conditions (moisture $\%)$ & $17.0 \%$ \\
\hline Pellet density $\left(\mathrm{lb} / \mathrm{ft}^{3}\right)$ & 39.42 \\
\hline Pellet durability & $98.70 \%$ \\
\hline Cooler & \\
Moisture removed & $1.70 \%$ \\
\hline Energy (kWh/dry ton) & 3.02 \\
\hline Throughput (dry ton/hour/machine) & 5 \\
\hline
\end{tabular}

a: The effective energy consumption is reduced because only $70 \%$ of the material is processed in Stage 2 due to fractional milling. The effective throughput is improved because only $70 \%$ of the material is processed in Stage 2 due to fractional milling

\section{A.5 Transportation and Handling}

The 2020 Herbaceous SOT incorporates both bale and pellet transportation. Baled biomass is shipped from field side storage to the depots, while pelleted blendstocks are shipped from depots to the biorefinery. Transportation operations include truck transportation and loading/unloading. Design assumptions for transportation and handling are outlined in Table A-7. Transportation and handling comprises all steps involved in the movement of biomass from multiple local locations to a centralized location (such as a preprocessing facility or biomass depot), including loading, trucking, and unloading. Like the 2019 Herbaceous SOT, the 2020 SOT uses the faster and more efficient Advanced Load Securing System (ALSS) developed in the AGCO-led High-Tonnage Feedstock Logistics project (Webb et al. 2013a), and ensures that each load meets transportation regulations (Figure A-4) using industry data for loading and unloading times. By automating the operation, the ALSS allows the load to be secured without the driver leaving the cab of the tractor (STINGER 2015). The ALSS is reported to load an entire truck in as little as 6 minutes (STINGER 2015). Additional handling operations are required to transfer and queue biomass during preprocessing, and to transfer the blended feedstock to the pretreatment reactor. Surge bins, conveyors, and a truck tipper are used in handling operations. 


\section{Idaho National Laboratory}

Table A-7. Transportation and handling design assumptions in the 2020 Herbaceous SOT.

Component

Three-pass corn Stover

Two-pass corn Stover

\section{Biomass characteristics during transportation from field to depot}

\begin{tabular}{|c|c|c|}
\hline Format & Bale & Bale \\
\hline Density & $12 \mathrm{lb} / \mathrm{ft}^{3}$ & $12 \mathrm{lb} / \mathrm{ft}^{3}$ \\
\hline Moisture content & $20 \%$ & $20 \%$ \\
\hline \multicolumn{3}{|c|}{ Biomass characteristics during transportation from depot to biorefinery } \\
\hline Format & Bulk pellets & Bulk pellets \\
\hline Density & $39.42 \mathrm{lb} / \mathrm{ft}^{3}$ & $39.42 \mathrm{lb} / \mathrm{ft}^{3}$ \\
\hline Moisture content & $11.53 \%$ & $11.53 \%$ \\
\hline \multicolumn{3}{|c|}{ Truck used during both transportation from field to depot and depot to biorefinery } \\
\hline Speed & $50 \mathrm{miles} /$ hour & 50 miles/hour \\
\hline Type & Day cab & Day cab \\
\hline \multicolumn{3}{|c|}{ Trailer used during transportation from field to depot } \\
\hline Type & 53-ft flatbed with ALSS & 53-ft flatbed with ALSS \\
\hline Volume & $3,600 \mathrm{ft}^{3}$ & $3,600 \mathrm{ft}^{3}$ \\
\hline \multicolumn{3}{|c|}{ Trailer used during transportation from depot to biorefinery } \\
\hline Type & Trailer "Live Floor" 48 feet 2 -axle & Trailer "Live Floor" 48 feet 2 -axle \\
\hline Volume & $3,600 \mathrm{ft}^{3}$ & $3,600 \mathrm{ft}^{3}$ \\
\hline \multicolumn{3}{|l|}{ Bale Loader } \\
\hline Capacity & 120 tons/hour & 120 tons/hour \\
\hline
\end{tabular}

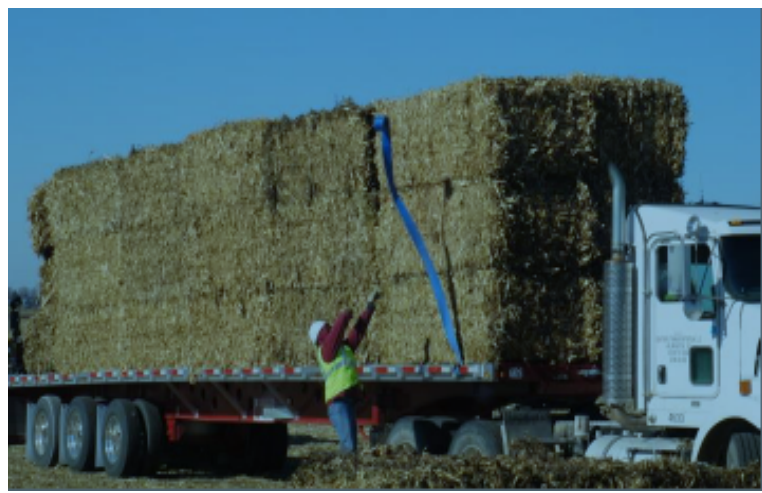

(a) Manual bale securing system

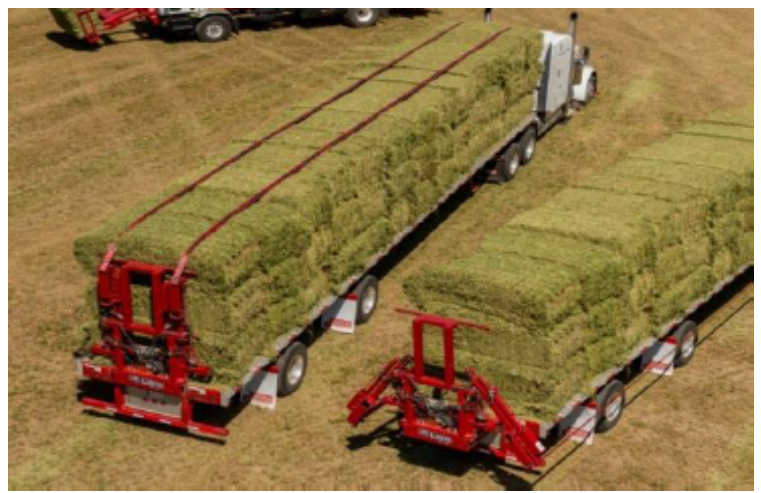

(b) Advanced load securing system

Figure A-4. Advanced Load Securing System (ALSS) replacing intense physical requirements to secure a load of bales in 2020 SOT (Source: Stinger) 


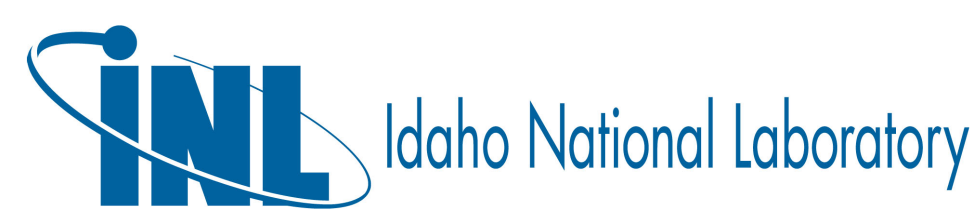

Flowability is defined as the relative movement of bulk particles in comparison to neighboring particles and is a measurement of the cohesion and shear stresses in bulk materials. Ground materials (such as bulk corn stover) tend to bridge and clog openings. Flow obstruction, bridging, or arching in addition to inconsistent and unreliable movement of material are common problems in biomass handling and reactor feeding. Figure A-6 shows three common issues experienced in material handling. Arching (bridging) occurs when an arch-shaped obstruction forms above the hopper outlet and stops flow. Ratholing (funneling) occurs when discharge takes place only in a flow channel located above the outlet; once the central flow channel is empty, flow stops. Finally, incomplete clean-out is when not all of the material empties from the sides of the holding container. To address these characteristics, the 2020 Herbaceous SOT incorporates densification to improve feedstock flowability.

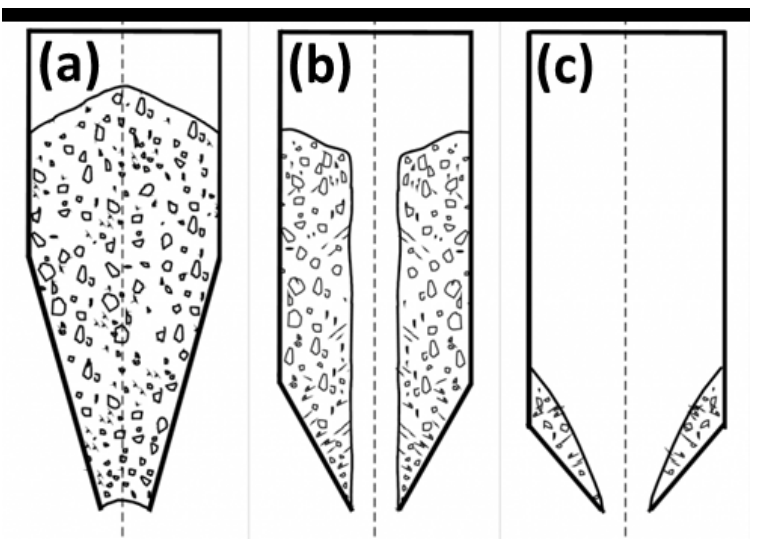

Figure A-5. Common flow and handling issues encountered when handling biomass. (a) Cohesive arch;

(b) Rathole; and (c) Incomplete cleanout. (Source: www.pharmtech.com)

The 2020 Herbaceous SOT estimates transportation cost based on biomass physical characteristics and equipment used during transportation. Transportation cost has two components, the distance variable cost (DVC) and the distance fixed cost (DFC). The distance variable cost includes the cost of fuel and labor, while the distance fixed cost includes the cost of loading and unloading the truck. Linear regressions were performed to estimate DVC and DFC for each of the biomass bale and blendstock pellet types based on the transportation and handling design assumptions shown above in Table A-8. The regression models were used to estimate the DVC of corn stover and switchgrass bales at $\$ 0.114 /$ dry ton/mile, while the DFC for bale transportation was estimated at $\$ 3.42 /$ dry ton. The DVC for corn stover was estimated to be $\$ 0.083 /$ dry ton/mile with the DFC estimated at $\$ 0.841 /$ dry ton. The values of DVC and DFC were utilized in the expanded least cost optimization model (Roni et al., 2018) to determine the cost-optimum resource usage based on both transportation distance and grower payment. The total transportation costs for bales and pellets (including loading and unloading) are shown as a function of distance from the biorefinery in Table A-8.

Table A-8. Total transportation costs for biomass bales and blendstock pellets. 
Idaho National Laboratory

\begin{tabular}{|c|c|c|}
\hline Distance (mi) & $\begin{array}{c}\text { Bale Transportation Costs } \\
\text { (\$/dry ton) }\end{array}$ & $\begin{array}{l}\text { Pelleted Blendstock Transportation Costs } \\
\text { (\$/dry ton) }\end{array}$ \\
\hline 10 & $\$ 4.57$ & $\$ 1.66$ \\
\hline 20 & $\$ 5.72$ & $\$ 2.49$ \\
\hline 30 & $\$ 6.83$ & $\$ 3.33$ \\
\hline 40 & $\$ 8.00$ & $\$ 4.16$ \\
\hline 50 & $\$ 9.12$ & $\$ 4.95$ \\
\hline 60 & $\$ 10.24$ & $\$ 5.79$ \\
\hline 70 & $\$ 11.40$ & $\$ 6.63$ \\
\hline 80 & $\$ 12.52$ & $\$ 7.46$ \\
\hline 90 & $\$ 13.69$ & $\$ 8.26$ \\
\hline 100 & $\$ 14.80$ & $\$ 9.09$ \\
\hline 120 & $\$ 17.09$ & $\$ 10.76$ \\
\hline 140 & $\$ 19.37$ & $\$ 12.39$ \\
\hline 160 & $\$ 21.66$ & $\$ 14.07$ \\
\hline 180 & $\$ 23.95$ & $\$ 15.69$ \\
\hline 200 & $\$ 26.23$ & $\$ 17.38$ \\
\hline 220 & $\$ 28.46$ & $\$ 19.00$ \\
\hline 240 & $\$ 30.74$ & $\$ 20.68$ \\
\hline
\end{tabular}

Once the optimum resource supply, volume and depot locations were determined, an average weighted transportation distance was calculated for the different types of biomass and the pelleted blendstocks. Table A-9 summarizes the transported biomass, weighted transportation distance and average transportation cost for various biomass and pellet from field to depot and depot to biorefinery in the 2020 Herbaceous SOT. The average weighted transportation distances from field to biorefinery of three-pass corn stover and two-pass corn stover were 100.29 miles and 115.77 miles respectively. 


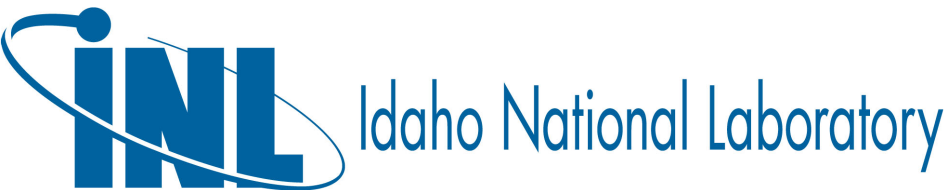

Table A-9. Summary of transported biomass, weighted transportation distance and average transportation cost for various biomass and pellet from field to depot and depot to biorefinery in the 2020 Herbaceous SOT case.

\begin{tabular}{lccccc|cc}
\hline & & \multicolumn{3}{c}{ Fields to Depots } & \multicolumn{3}{c}{ Depots to Biorefinery } \\
\cline { 3 - 8 } $\begin{array}{c}\text { Biomass } \\
\text { Type }\end{array}$ & $\begin{array}{c}\text { Raw } \\
\text { Biomass } \\
\text { Purchased } \\
\text { (dry tons) }\end{array}$ & $\begin{array}{c}\text { Biomass } \\
\text { Trans- } \\
\text { ported } \\
\text { (dry } \\
\text { tons) }\end{array}$ & $\begin{array}{c}\text { Weighted } \\
\text { Trans- } \\
\text { portation } \\
\text { Distance } \\
\text { (miles) }\end{array}$ & $\begin{array}{c}\text { Average } \\
\text { Trans- } \\
\text { portation } \\
\text { cost } \mathbf{( \$ /} \\
\text { dry ton) }\end{array}$ & $\begin{array}{c}\text { Pellets } \\
\text { Trans- } \\
\text { ported } \\
\text { (dry } \\
\text { tons) }\end{array}$ & $\begin{array}{c}\text { Weighted } \\
\text { Trans- } \\
\text { portation } \\
\text { Distance } \\
\text { (miles) }\end{array}$ & $\begin{array}{c}\text { Average } \\
\text { Trans- } \\
\text { portation } \\
\text { cost }(\$ / \\
\text { dry ton) }\end{array}$ \\
\hline $\begin{array}{l}\text { Three-pass } \\
\text { corn stover }\end{array}$ & 240,350 & 219,199 & 38.01 & $\$ 7.66$ & 214,815 & 62.28 & $\$ 5.91$ \\
\hline $\begin{array}{l}\text { Two-pass } \\
\text { corn stover }\end{array}$ & 570,830 & 520,597 & 36.43 & $\$ 7.48$ & 510,185 & 79.34 & $\$ 7.30$ \\
\hline Blended & 811,180 & 739,796 & 36.90 & 7.54 & 725,000 & 74.28 & 6.89 \\
\hline
\end{tabular}

\section{A.6 Depot construction cost for different depot sizes}

Construction and infrastructure costs for depots were estimated as follows. For a fixed depot size, the total installed capital investment cost per ton was estimated for the preprocessing, storage and handling operations in the depot. The installed capital cost included all preprocessing, handling and storage equipment; the estimate included instrumentation and control, piping and electrical installation, yard improvement, engineering and supervision, contractor fees, construction and contingency. To estimate the capital layout for construction and infrastructure for individual preprocessing equipment similar to the equipment in this design, an installation factor value of 1.49 was applied, estimated based on Peters et al. (1968). Land cost was calculated assuming 160 acres per distributed depot (including onsite bale storage) at a cost of $\$ 500 /$ acre and was added to the capital cost to determine the loan amount. The required acreage for a 725,000 dry tons/year depot (including onsite bale storage) was estimated at 226 acres. The total cost was amortized over 30 years, assuming a $20 \%$ down payment and an $8 \%$ interest rate, and divided by the number of delivered tons to give the per ton cost of depot construction and infrastructure, which totaled $\$ 2.30$ /dry ton for a depot scaled to 725,000 dry tons/year. The above steps were repeated for depot scales ranging from 25,000-700,000 dry tons/year, and the results are shown in Figure A-7. 


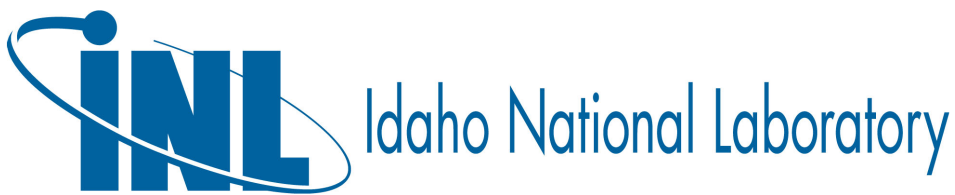

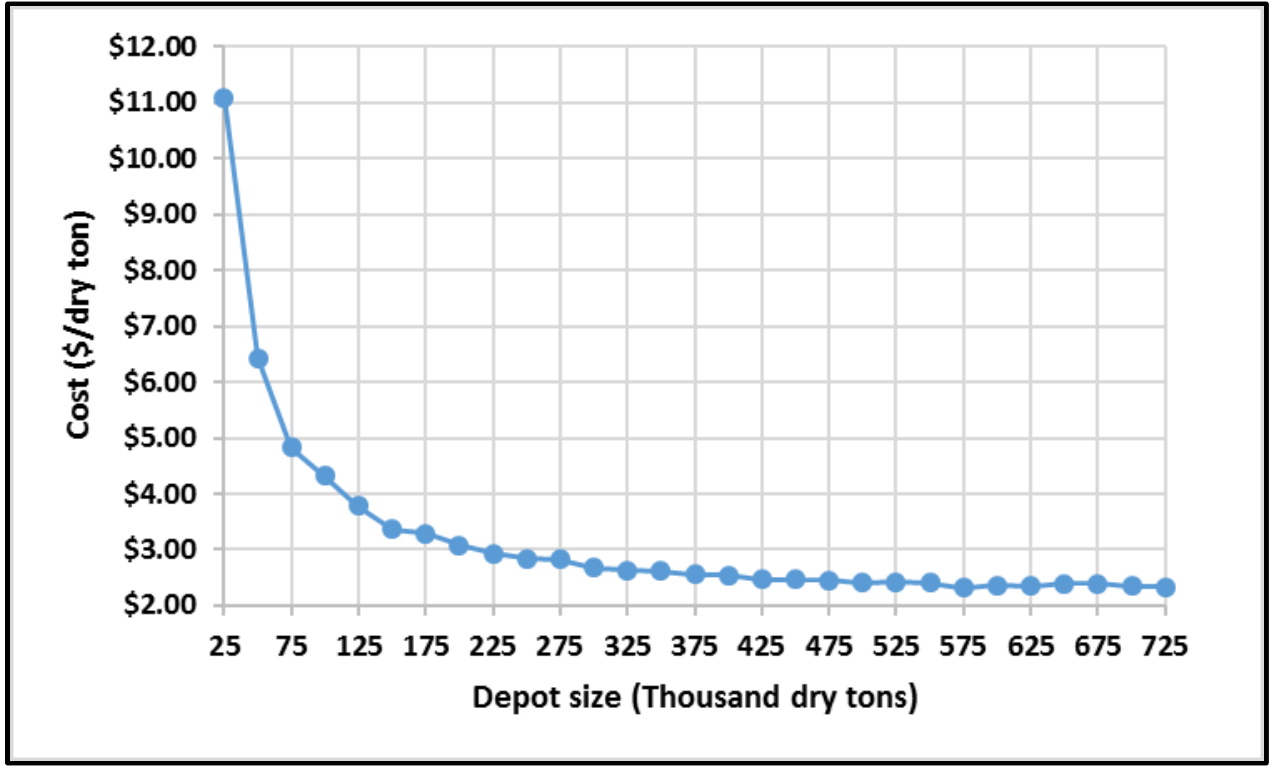

Figure A-7. Estimated depot construction costs as a function of depot scale.

\section{A.7 Blending}

Pellets of each individual blendstock are conveyed into separate storage bins upon receipt from the depots. Pellets are blended in the biorefinery just prior to introduction to the pretreatment reactor feeding system and are blended to the desired ratio during conveyance to the feeder. The three-pass corn stover and two-pass corn stover pellets are blended at a ratio of $29.63 \% / 70.37$ respectively, and the blend is conveyed to the throat of the pretreatment reactor.

\section{A.8 Cost Breakdown by Operation}

As described above, an ash dockage equivalent to the biorefinery cost of disposing of ash in excess of the ash specification is applied in the 2020 Herbaceous SOT. Ash disposal costs are assumed to be $\$ 37.63 /$ dry ton of ash (Davis et al. 2013). Delivering the feedstock blend at $10 \%$ rather than $20 \%$ moisture would incur a cost of to the biorefinery in the form of additional makeup water. This value was calculated from the assumed make-up water cost of $\$ 0.31 /$ ton of water used by Davis et al. (2013). Table A-11 shows the cost breakdown by operation for the individual blendstocks, while Table 12 provides cost information for the three storage types employed. 


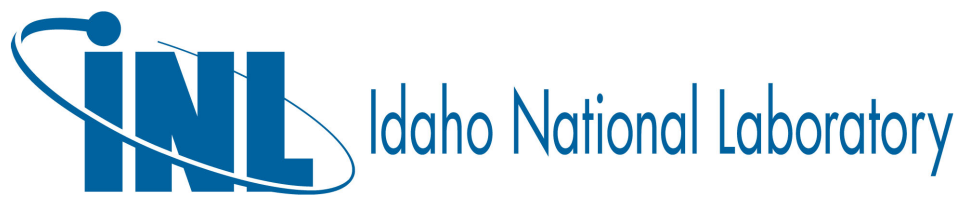

Table A-11. 2020 Herbaceous SOT modeled costs for production of blendstock pellets, by operation.

\begin{tabular}{|c|c|c|}
\hline Cost Element & $\begin{array}{l}\text { Three-Pass } \\
\text { Corn Stover } \\
\text { (\$/dry ton) }\end{array}$ & $\begin{array}{l}\text { Two-Pass } \\
\text { Corn Stover } \\
\text { (\$/dry ton) }\end{array}$ \\
\hline Grower payment & $\$ 21.71$ & $\$ 20.16$ \\
\hline Harvest and collection & $\$ 13.84$ & $\$ 18.79$ \\
\hline Combine & $\$ 0.00$ & $\$ 0.00$ \\
\hline Shredder & $\$ 4.10$ & - \\
\hline Baler & $\$ 6.29$ & $\$ 15.34$ \\
\hline Stacker & $\$ 3.45$ & $\$ 3.45$ \\
\hline Storage \& queuing & $\$ 6.66$ & $\$ 6.74$ \\
\hline Field side storage & $\$ 4.23$ & $\$ 4.31$ \\
\hline Depot storage & $\$ 0.88$ & $\$ 0.88$ \\
\hline Refinery storage & $\$ 0.12$ & $\$ 0.12$ \\
\hline Handling and queuing at depot & $\$ 1.20$ & $\$ 1.20$ \\
\hline Handling and queuing at refinery & $\$ 0.22$ & $\$ 0.22$ \\
\hline Transportation and handling & $\$ 13.74$ & $\$ 14.97$ \\
\hline Transportation from field to depot & $\$ 7.76$ & $\$ 7.58$ \\
\hline Transportation from depot to refinery & $\$ 5.99$ & $\$ 7.39$ \\
\hline In-plant receiving and preprocessing & $\$ 19.43$ & $\$ 19.43$ \\
\hline Depot construction cost & $\$ 2.52$ & $\$ 2.52$ \\
\hline Bale processor & $\$ 1.80$ & $\$ 1.80$ \\
\hline Hammer mill & $\$ 7.37$ & $\$ 7.37$ \\
\hline Densifier & $\$ 5.61$ & $\$ 5.61$ \\
\hline Cooling & $\$ 0.88$ & $\$ 0.88$ \\
\hline Conveyors & $\$ 0.16$ & $\$ 0.16$ \\
\hline Dust collection & $\$ 0.75$ & $\$ 0.75$ \\
\hline Surge bin & $\$ 0.05$ & $\$ 0.05$ \\
\hline Misc. Equipment ${ }^{\mathrm{a}}$ & $\$ 0.21$ & $\$ 0.21$ \\
\hline Blending & $\$ 0.07$ & $\$ 0.07$ \\
\hline Dockage & $\$ 2.59$ & $\$ 0.89$ \\
\hline Ash dockage & $\$ 2.56$ & $\$ 0.86$ \\
\hline Moisture dockage & $\$ 0.03$ & $\$ 0.03$ \\
\hline Total delivered blendstock cost & $\$ 77.97$ & $\$ 80.98$ \\
\hline
\end{tabular}

a Miscellaneous equipment consists of destringers, moisture meters, bale rejecters, electromagnets, etc. 
Table A-12. 2020 Herbaceous SOT modeled storage cost breakdown for three-pass corn stover and twopass corn stover.

\begin{tabular}{lccccccc}
\hline \multirow{2}{*}{ Component } & \multicolumn{2}{c}{ Storage TEA parameters $\mathbf{1}$} & \multicolumn{2}{c}{ Storage TEA parameters 2} & \multicolumn{2}{c}{ Storage TEA parameters 3 } \\
\cline { 2 - 7 } & $\begin{array}{l}\text { Three-Pass } \\
\text { Corn Stover } \\
\text { (\$/dry ton) }\end{array}$ & $\begin{array}{c}\text { Two-Pass } \\
\text { Corn Stover } \\
\text { (\$/dry ton) }\end{array}$ & $\begin{array}{c}\text { Three-Pass } \\
\text { Corn Stover } \\
\text { (\$/dry ton) }\end{array}$ & $\begin{array}{c}\text { Two-Pass } \\
\text { Corn Stover } \\
\text { (\$/dry ton) }\end{array}$ & $\begin{array}{c}\text { Three-Pass } \\
\text { Corn Stover } \\
\text { (\$/dry ton) }\end{array}$ & $\begin{array}{c}\text { Two-Pass } \\
\text { Corn Stover } \\
\text { (\$/dry ton) }\end{array}$ \\
\hline Storage cost & $\$ 5.54$ & $\$ 5.49$ & $\$ 1.84$ & $\$ 1.85$ & $\$ 1.84$ & $\$ 1.85$ \\
\hline $\begin{array}{l}\text { Dry matter loss } \\
\text { cost }\end{array}$ & $\$ 0.82$ & $\$ 0.87$ & $\$ 2.00$ & $\$ 2.12$ & $\$ 1.31$ & $\$ 1.38$ \\
\hline $\begin{array}{l}\text { Total storage } \\
\text { cost }\end{array}$ & $\$ 6.36$ & $\$ 6.36$ & $\$ 3.85$ & $\$ 3.97$ & $\$ 3.15$ & $\$ 3.23$ \\
\hline
\end{tabular}




\section{Idaho National Laboratory}

\section{APPENDIX B $-\mathrm{n}^{\text {th }}$-Supply Scenario Assumptions and Analysis}

Authors: Tasmin Hossain ${ }^{1}$, Daniela Jones ${ }^{1,2}$, Damon Hartley ${ }^{2}$, Mike Griffel ${ }^{2}$, Yingqian Lin $^{2}$, Pralhad Burli², David N. Thompson ${ }^{2}$, Matthew Langholtz ${ }^{3}$, Maggie Davis ${ }^{3}$, Craig Brandt ${ }^{3}$

${ }^{1}$ Biological \& Agricultural Engineering, North Carolina State University, Raleigh, NC

${ }^{2}$ Bioenergy Analysis, Idaho National Laboratory, Idaho Falls, ID

${ }^{3}$ Environmental Sciences Division, Oak Ridge National Laboratory, Oak Ridge, TN

Addressing biomass cost and quality targets is an important BETO Feedstock Technologies (FT) Platform objective. Many of the targets are assumed to be for an $\mathrm{n}^{\text {th }}$-plant scenario, however, assumptions are based in present time. For example, for resource availability both quantity and types of materials are viewed in terms of what is currently available. Further, the attributes that define the $\mathrm{n}^{\text {th }}$-Plant scenario are not clear and may be inconsistent across the analysis projects. Additionally, assumptions to quantify harvest cost, grower payment, and farmgate price, may also differ across projects. Preemptively harmonizing assumptions with other FT projects, in particular, the definition of the $\mathrm{n}^{\text {th }}$-supply scenario parameters as well as operational parameters such as harvest cost as a function of per-acre yield and profit margin to the grower, will make results across FT projects more comparable and consistent. In this task, analysts at INL and ORNL worked together to define a consistent set of parameters that define the $\mathrm{n}^{\text {th }}$ supply scenario and supply chain parameters, and annually review operational assumptions to maintain alignment across FT-funded analyses.

Through this work, a set of operational cost assumptions was harmonized and used in feedstock logistic models at INL and ORNL such as the Least-Cost Formulation, POLYSYS, and the Supply Characterization Models. A two-step process was used to reduce the problem size using a modified version of INL's Least-Cost Formulation model, a Mixed Integer Linear Programming (MILP) Model, to model the delivery of on-spec biomass of multiple crops that considers biomass quantity and quality at a specified total delivered feedstock cost. The first step was to determine a set of candidate locations for biorefineries and depots nationwide. In the second step, biorefineries and depots of different capacity sizes were located using different scenarios.

Using the acids pathway fuel yield of $44.8 \mathrm{GGE} /$ dry ton presented by Davis et al. (2018), our case study for 2022, which located a total of 59 biorefineries (42.8M dry tons), translates to 1.9 billion GGE. Only $0.12 \%$ of the RFS 2 targets to produce 16 billion gallons of cellulosic biofuels by 2022 could be achieved with corn stover and switchgrass. Additionally, based on this analysis, only $29.68 \mathrm{M}$ dry tons of switchgrass and corn stover could be delivered at $\$ 71.26$ per dry ton $(2016 \$)$ delivered to the pretreatment reactor throat by 2030 . These translates into 41 
biorefineries, or 1.3 billion GGE. Hence, the decrease in targeted cost per dry ton delivered from $\$ 79.07$ in 2022 to $\$ 71.26$ in 2030 , decreases the feasible production of biofuels by 0.6 billion GGE.

\section{B.1 Harmonized herbaceous operational assumptions}

Logistics costs in different formats were harmonized based on the required input parameters for the different feedstock logistic models at INL and ORNL such as the Least-Cost Formulation, POLYSYS, and the Supply Characterization Models. Note that biomass sorghum was not one of the feedstocks considered in Roni et al. (2018). Table B.1 and Table B.2 present inputs used for analysis at ONRL based on joint-efforts to harmonize operational costs. Table B.3 and Table B.4 present inputs used for analysis at INL based on joint-efforts to harmonize operational costs.

Table B.2 Comparison of costs used in a conventional supply chain in the BT16 (USDOE 2016), the 2018 Herbaceous State of Technology Report (SOT) (Roni et al. 2018) costs translated for a conventional supply chain, and harmonized costs assumptions for a conventional supply chain in a format to be used by the models at ORNL.

\begin{tabular}{|c|c|c|c|}
\hline \multirow{2}{*}{ Farmgate to biorefinery operation } & \multicolumn{3}{|c|}{ Costs, $\$ \mathrm{Mg}^{-1}\left(\$\right.$ ton $\left.^{-1}\right)$} \\
\hline & BT16 $^{1}$ & 2018 SOT $^{2}$ & Harmonized \\
\hline \multicolumn{4}{|l|}{ Corn stover } \\
\hline Storage on-farm & $4.32(3.92)$ & $4.38(3.97)$ & $4.38(3.97)$ \\
\hline Field side handling and queuing & $3.57(3.24)$ & $3.77(3.42)$ & $3.77(3.42)$ \\
\hline Storage at biorefinery & $1.73(1.57)$ & $0.97(0.88)$ & $0.97(0.88)$ \\
\hline Grinding & $15.43(14)$ & $13.15(11.93)$ & $13.15(11.93)$ \\
\hline Handling at biorefinery & - & $2.93(2.66)$ & $2.93(2.66)$ \\
\hline Dockage for moisture & $3.7(3.36)$ & $0.03(0.03)$ & $3.7(3.36)$ \\
\hline Dockage for ash & $2.99(2.71)$ & $2.99(2.71)$ & $2.99(2.71)$ \\
\hline Total & $31.75(28.8)$ & $27.98(25.38)$ & $31.65(28.71)$ \\
\hline \multicolumn{4}{|l|}{ Switchgrass and Miscanthus } \\
\hline Storage on-farm & $4.32(3.92)$ & $3.33(3.02)$ & $3.33(3.02)$ \\
\hline Field side handling and queuing & $3.57(3.24)$ & $1.48(1.34)$ & $3.77(3.42)$ \\
\hline Storage at biorefinery & $1.73(1.57)$ & $0.97(0.88)$ & $0.97(0.88)$ \\
\hline Grinding & $15.43(14)$ & $10.38(9.42)$ & $10.38(9.42)$ \\
\hline Handling at biorefinery & - & $2.98(2.70)$ & $2.98(2.70)$ \\
\hline Dockage for moisture & $3.7(3.36)$ & $0.03(0.03)$ & $3.7(3.36)$ \\
\hline Dockage for ash & $2.57(2.33)$ & $0.58(0.53)$ & $2.57(2.33)$ \\
\hline Total & $31.33(28.42)$ & $19.75(17.92)$ & $27.7(25.13)$ \\
\hline
\end{tabular}

${ }^{1} \$ 2014,{ }^{2} \$ 2016$

Table B.3 (Continued)

Farmgate to biorefinery operation

Costs, $\$ \mathrm{Mg}^{-1}\left(\$\right.$ ton $\left.^{-1}\right)$ 


\begin{tabular}{|c|c|c|c|}
\hline & BT16 $^{1}$ & 2018 SOT $^{2}$ & Harmonized \\
\hline \multicolumn{4}{|c|}{ Biomass sorghum } \\
\hline Module building & $9.14(8.29)$ & - & $9.14(8.29)$ \\
\hline Storage & $4.32(3.92)$ & - & $4.32(3.92)$ \\
\hline Load truck & $7.9(7.17)$ & - & $7.9(7.17)$ \\
\hline Storage at biorefinery & $1.73(1.57)$ & - & $1.73(1.57)$ \\
\hline Grinding & $9.14(8.29)$ & - & $9.14(8.29)$ \\
\hline Dockage for moisture & $7.41(6.72)$ & - & $7.41(6.72)$ \\
\hline Dockage for ash & $2.99(2.71)$ & - & $2.99(2.71)$ \\
\hline Total & $42.63(38.67)$ & - & $42.63(38.67)$ \\
\hline
\end{tabular}

\$2014, ${ }^{2} \$ 2016$

Table B.4 Harmonized costs assumptions for an advanced supply chain in a format to be used by the models at ORNL.

\begin{tabular}{|c|c|c|}
\hline \multirow[b]{2}{*}{ Farmgate to depot to biorefinery operation } & \multicolumn{2}{|c|}{ Costs, $\$ \mathrm{Mg}^{-1}\left(\right.$ \$ ton $\left.^{-1}\right)$} \\
\hline & Corn stover & $\begin{array}{l}\text { Switchgrass and } \\
\text { Miscanthus }\end{array}$ \\
\hline Storage and queuing & $7.05(6.4)$ & $6.49(5.89)$ \\
\hline Field & $4.38(3.97)$ & $3.33(3.02)$ \\
\hline Depot & $2.3(2.09)$ & $2.45(2.22)$ \\
\hline Biorefinery & $0.37(0.34)$ & $0.72(0.65)$ \\
\hline In-plant receiving and processing & $24.97(22.65)$ & $24.31(22.05)$ \\
\hline Field & $0(0)$ & $0(0)$ \\
\hline Depot & $24.97(22.65)$ & $24.31(22.05)$ \\
\hline Biorefinery & $0(0)$ & $0(0)$ \\
\hline Dockage for ash and moisture & $3.02(2.74)$ & $0.62(0.56)$ \\
\hline Field & $0(0)$ & $0(0)$ \\
\hline Depot & $0(0)$ & $0(0)$ \\
\hline Biorefinery & $3.02(2.74)$ & $0.62(0.56)$ \\
\hline Fixed cost load and unload from farm to depot & $3.77(3.42)$ & $3.77(3.42)$ \\
\hline Fixed cost load and unload from depot to biorefinery & $0.91(0.83)$ & $0.87(0.79)$ \\
\hline Cost per hour from farmgate & $4.43(4.02)$ & $4.43(4.02)$ \\
\hline Cost per mile from farmgate & $0.04(0.03)$ & $0.04(0.03)$ \\
\hline Cost per hour from depot & $3.22(2.92)$ & $3.18(2.89)$ \\
\hline Cost per mile from depot & $0.03(0.02)$ & $0.03(0.02)$ \\
\hline
\end{tabular}

Table B.5 Harmonized cost assumptions for the conventional supply chain in a format to be used by the Least-Cost Formulation model at INL. CS3P = Three-pass corn stover, CS $2 P=$ Two-pass corn stover and $S W=$ Switchgrass. 


\begin{tabular}{|c|c|c|c|c|}
\hline Cost Description & Feedstock & Location & CS3P CS2P & SW \\
\hline Farmgate Price & Bale & Field & $\$ 30-90^{1}$ & $\$ 40-90^{1}$ \\
\hline Storage & Bale & Field & $\$ 3.97 \$ 4.10$ & $\$ 3.02$ \\
\hline Storage, Handling and Queuing & Bale & Biorefinery & $\$ 3.54$ & $\$ 4.01$ \\
\hline Processing Cost & Bale to fuel & Biorefinery & $\$ 11.93$ & $\$ 9.42$ \\
\hline Ash Dockage & Bale & Biorefinery & $\$ 6.19 \$ 2.24$ & $\$ 5.69$ \\
\hline Moisture Dockage & Bale & Biorefinery & $\$ 0.00 \$ 0.00$ & $\$ 0.00$ \\
\hline $\begin{array}{l}\text { Transportation Fixed Cost or } \\
\text { Fieldside Handling and Oueuing }\end{array}$ & Bale & Field to Biorefinery & \multicolumn{2}{|l|}{$\$ 3.42$} \\
\hline Transportation Variable Cost & Bale & Field to Biorefinery & \multicolumn{2}{|c|}{$\$ 0.114^{2}$} \\
\hline
\end{tabular}

${ }^{1} 2014 \$,{ }^{2} \$ /$ mile/dry ton

Table B.6 Harmonized cost assumptions for the advanced supply chain in a format to be used by the Least-Cost Formulation model and the study presented in this report. CS3P $=$ Three-pass corn stover, CS2P = Two-pass corn stover and $S W=$ Switchgrass.

\begin{tabular}{|c|c|c|c|c|c|}
\hline \multirow[t]{2}{*}{ Cost Description } & \multirow{2}{*}{$\begin{array}{l}\text { Feedstock } \\
\text { Format }\end{array}$} & \multirow[t]{2}{*}{ Location } & \multicolumn{3}{|c|}{ Feedstock } \\
\hline & & & CS3P & CS2P & SW \\
\hline Farmgate Price & Bale & Field & \multicolumn{2}{|c|}{$\$ 30-90^{1}$} & $\$ 40-90^{1}$ \\
\hline Storage & Bale & Field & $\$ 3.97$ & $\$ 4.10$ & $\$ 3.02$ \\
\hline Storage, Handling and Queuing & Bale to pellets & Depot & \multicolumn{2}{|c|}{$\$ 2.09$} & $\$ 2.22$ \\
\hline Storage, Handling and Queuing & Pellets & Biorefinery & \multicolumn{2}{|c|}{$\$ 0.34$} & $\$ 0.65$ \\
\hline Processing Cost & Bale to pellets & Depot & \multicolumn{2}{|c|}{$\$ 19.47$} & $\$ 18.77$ \\
\hline Ash Dockage & Pellets & Biorefinery & $\$ 2.71$ & $\$ 0.98$ & $\$ 0.53$ \\
\hline Moisture Dockage & Pellets & Biorefinery & $\$ 0.03$ & $\$ 0.03$ & $\$ 0.03$ \\
\hline $\begin{array}{l}\text { Transportation Fixed Cost or Field- } \\
\text { side Handling and Queuing }\end{array}$ & Bale & Field to Depot & \multicolumn{3}{|c|}{$\$ 3.42$} \\
\hline Transportation Variable Cost & Bale & Field to Depot & \multicolumn{3}{|c|}{$\$ 0.114^{2}$} \\
\hline Transportation Fixed Cost & Pellets & $\begin{array}{l}\text { Depot to } \\
\text { Biorefinery }\end{array}$ & \multicolumn{2}{|c|}{$\$ 0.829$} & $\$ 0.792$ \\
\hline Transportation Variable Cost & Pellets & $\begin{array}{l}\text { Depot to } \\
\text { Biorefinery }\end{array}$ & \multicolumn{2}{|c|}{$\$ 0.082^{2}$} & $\$ 0.081^{2}$ \\
\hline
\end{tabular}

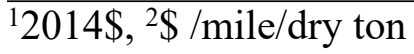

\section{B.2 Feedstock location and availability}




\section{Idaho National Laboratory}

The base-case scenario county-level feedstock values reported in the BT16 for corn stover and switchgrass (estimated to grow on cropland and pastureland) were analyzed including year 2022, 2030, and 2040 (Langholtz et al., 2016) (Figure B.1).

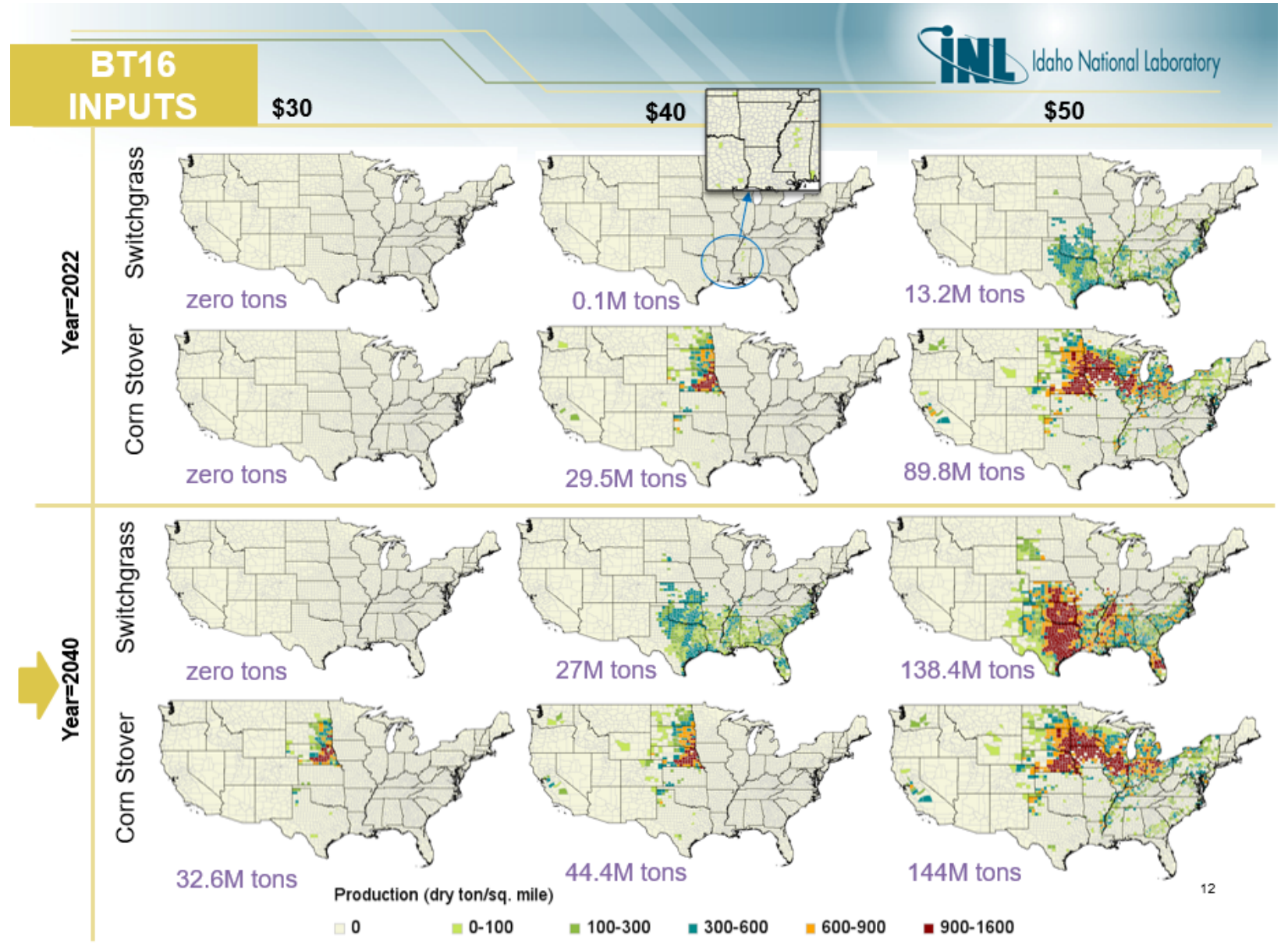

Figure B.1 BT16 biomass availability per county.

\section{B.3 Reducing the problem size and creating a demand run for POLYSYS}

Given the computational size of the problem scope, we used a two-step process to reduce the problem size using a modified version of INL's Least-Cost Formulation model, a Mixed Integer Linear Programming (MILP) Model to deliver on-spec biomass of multiple crops that considers biomass quantity and quality at a specified total delivered feedstock cost. The first step was to determine a set of candidate locations for biorefineries and depots nationwide. In the second step, biorefineries and depots of different capacity sizes were located using different scenarios. In that analysis, 263 depots were supplied with 70,711,935 dry tons of corn stover from 416 sources and 32,316,373 dry tons of switchgrass from 751 sources (Figure B.2). 

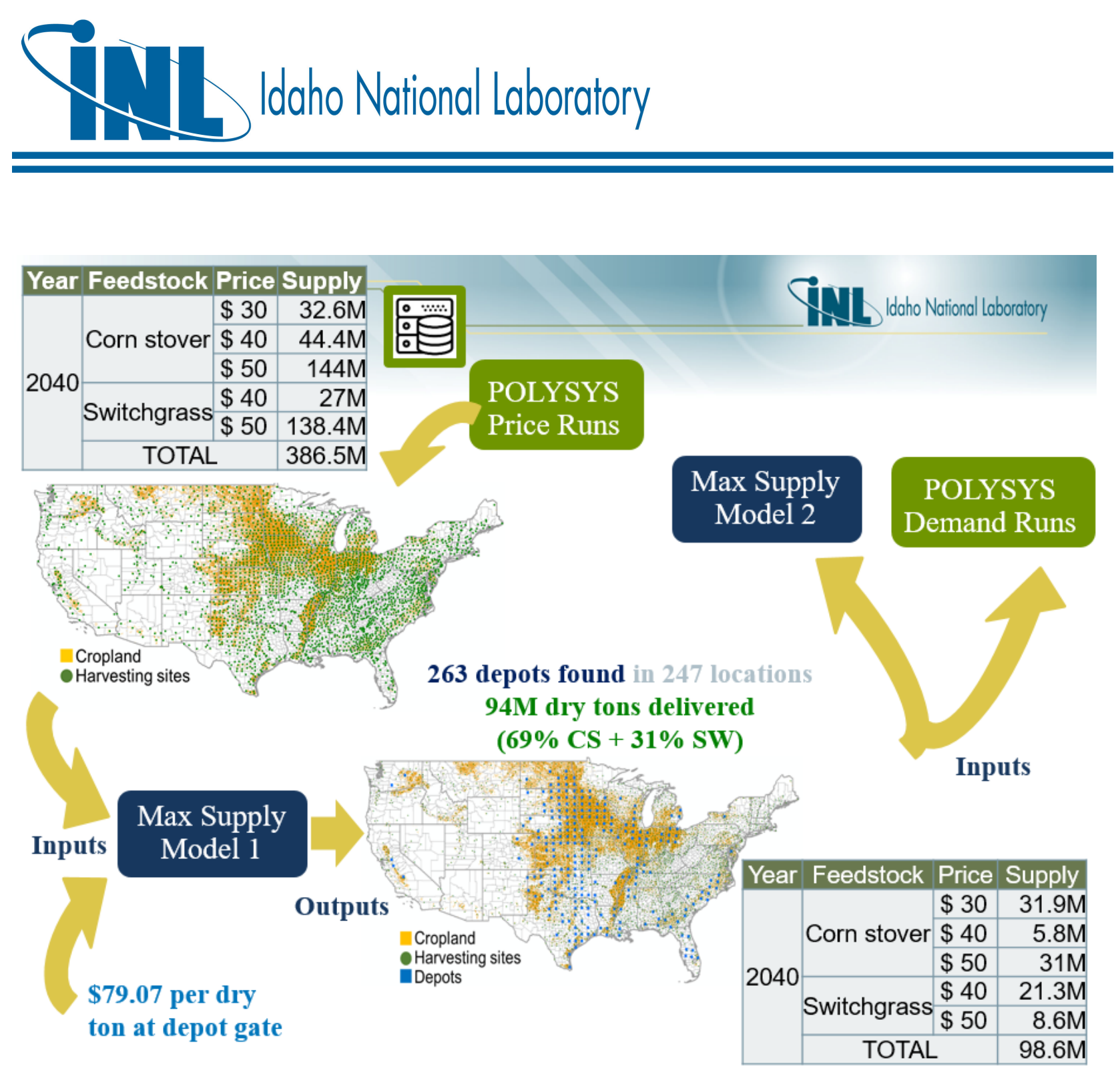

Figure B2. Reducing the problem size and creating a demand run for POLYSYS.

\section{B.4 POLYSYS demand run}

In efforts to further harmonize our model with POLYSYS demand and supply runs (in green), we used the MILP outputs (263 potential depot locations) as inputs to demand runs for POLYSYS. Note that with the demand runs, in total, more biomass becomes available. While switchgrass estimations are higher at both farmgate prices, corn stover increases are only seen in the $\$ 40$ and $\$ 50$ price levels (Figure B.3). The outputs from the POLYSYS demand runs were also inputs to the MILP presented in this study to find biorefineries and depots and the results are presented in Table B.5 


\section{SW Idaho National laboritory}

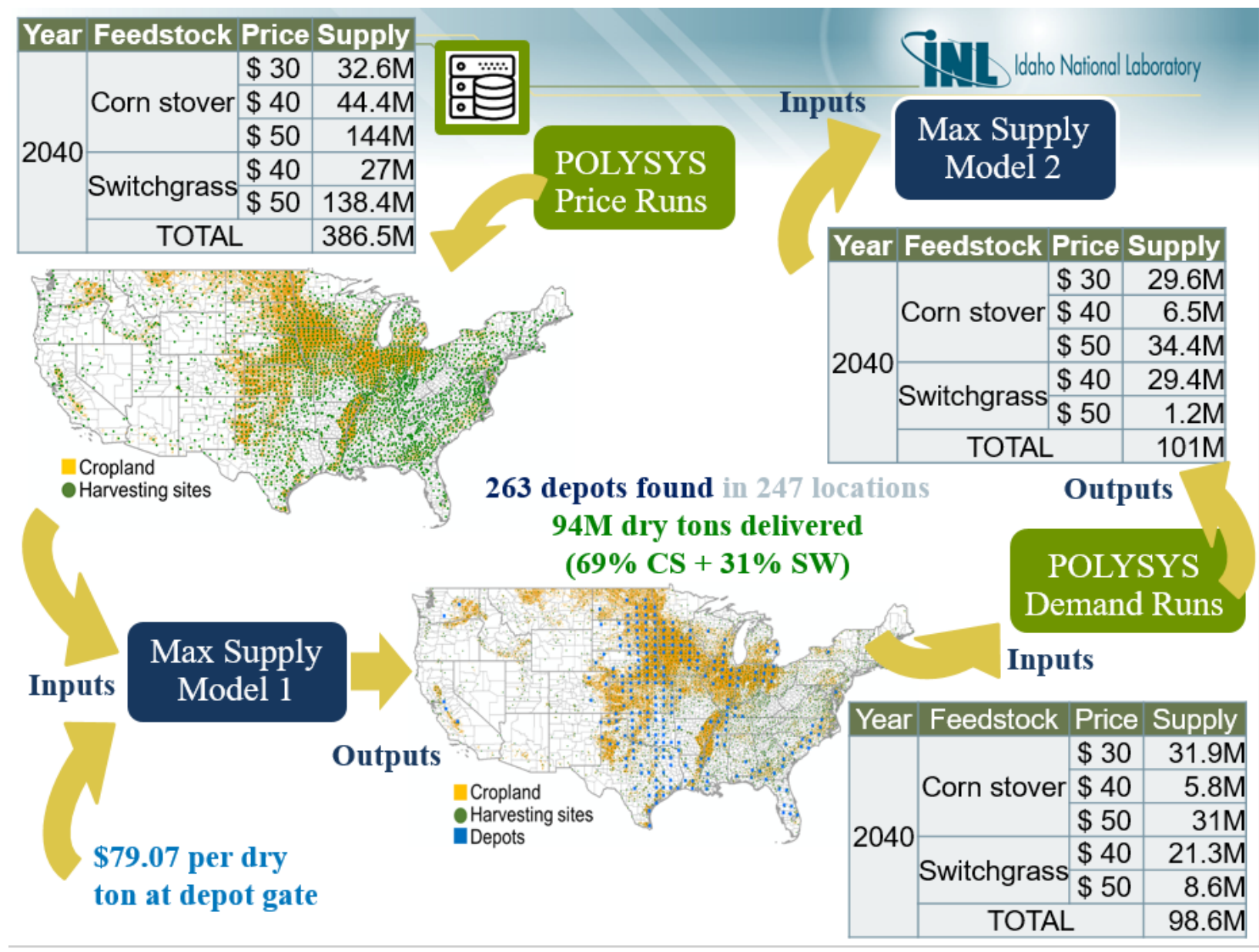

Figure B.3 POLYSYS demand runs

Table B.5 Locating Biorefineries and Depots from the POLYSYS demand runs

\begin{tabular}{|c|c|c|c|c|c|c|}
\hline \multicolumn{2}{|c|}{ Scenario } & $\begin{array}{l}\$ 30 \\
(d t)\end{array}$ & $\begin{array}{l}\$ 40 \\
(d t)\end{array}$ & $\begin{array}{l}\$ 50 \\
(d t)\end{array}$ & $\begin{array}{l}\text { Total } \\
\text { (dt) }\end{array}$ & $\begin{array}{l}\text { Number of } \\
\text { Facilities }\end{array}$ \\
\hline \multirow{3}{*}{$\begin{array}{l}\$ 79.07 \\
\text { /dry ton }\end{array}$} & SW & - & $31 \mathrm{M}$ & $1 \mathrm{M}$ & $32 \mathrm{M}(36 \%)$ & \multirow{4}{*}{$\begin{array}{c}210 \text { Depots, } 125 \\
\text { Biorefineries }\end{array}$} \\
\hline & CS2P & $2 \mathrm{M}$ & $12 \mathrm{M}$ & $12 \mathrm{M}$ & $26 \mathrm{M}(29 \%)$ & \\
\hline & CS3P & $22 \mathrm{M}$ & $2 \mathrm{M}$ & $8 \mathrm{M}$ & $32 \mathrm{M}(35 \%)$ & \\
\hline \multicolumn{5}{|c|}{ Total feedstock collected } & $90.6 \mathrm{M}$ & \\
\hline
\end{tabular}




\section{B.4 $\mathbf{n}^{\text {th }}$-Supply Scenario References}

Davis, R. E., Grundl, N. J., Tao, L., Biddy, M. J., Tan, E. C., Beckham, G. T., ... \& Roni, M. S. (2018). Process Design and economics for the conversion of lignocellulosic biomass to hydrocarbon fuels and coproducts: 2018 biochemical design case update; biochemical deconstruction and conversion of biomass to fuels and products via integrated biorefinery pathways (NREL/TP-5100-71949). National Renewable Energy Lab. (NREL), Golden, CO (United States).

Langholtz, M. H., Stokes, B. J., \& Eaton, L. M. (2016). 2016 Billion-ton report: Advancing domestic resources for a thriving bioeconomy, Volume 1: Economic availability of feedstock. Oak Ridge National Laboratory, Oak Ridge, Tennessee, managed by UT-Battelle, LLC for the US Department of Energy, 2016, 1-411.

Roni, M. S., Hartley, D. S., Griffel, M., Hu, H., Nguyen, Q. A., Cai, H., \& Thompson, D. N. (2020). Herbaceous feedstock 2018 state of technology report (INL/EXT-18-51654-Rev000). Idaho National Laboratory (INL), Idaho Falls, ID (United States). 